\title{
VIDA COTIDIANA \\ DE LOS CERAMISTAS Y VIDRIEROS BARCELONESES
}

\author{
Ma CARMEN RIU DE MARTÍN $^{1}$
}

\begin{abstract}
Resumen: Estudio sobre la actividad cotidiana de los ceramistas y vidrieros barceloneses a fines de la Edad Media y principios de la Edad Moderna. Trata tanto aspectos relacionados con la cultura material (joyas, objetos curiosos, rosarios, libros, vestidos, etc..), como las piezas de cerámica y vidrio que albergaban en sus domicilios. Se analizan además, elementos relacionados con el taller y la tienda, el tipo de piezas que elaboraban y algunas de las aficiones que estos artesanos poseían. Se basa en los inventarios y subastas de bienes que se encuentran en el Arxiu Històric de la Ciutat de Barcelona.
\end{abstract}

Palabras clave: cerámica; vidrio; joyas; retablos; capillas; indumentaria.

Abstract: This work studies the daily activity of ceramicists and glassblowers from Barcelona during the late medieval ages and the first part of modern period. It analyzes some aspects of the material culture (jewerly, curious objects, rosary beads, books, dresses, etc..), and also some ceramic and glass pieces that they had in their homes. Other details explained are related to the work place and the shop, some characteristics of the pieces made by them and some hobbies practised by these artisans. The documentation has been collected in Arxiu Históric de la Ciutat de Barcelona.

Keywords: ceramics; glass; jewelry; votive objects; dresses

\section{SUMARIO}

1. Los objetos de uso personal.- 2. Los vestidos, las joyas y los objetos curiosos.- 3 . Los objetos de cerámica.- 4. Los objetos de vidrio.- 5. El obrador y la tienda.- 6. Los precios y valores de algunos objetos.- Conclusiones.

El trabajo ha sido realizado a partir de material extraído del Archivo Histórico de la ciudad de Barcelona. Se basa en los inventarios y subastas de

\footnotetext{
${ }^{1}$ Secretaria de "Índice Histórico Español”. Barcelona. 2003.

Fecha de recepción del artículo: junio 2003. Fecha de aceptación y versión final: noviembre

«Anuario de Estudios Medievales», 34/1 (2004), pp. 307-355.- ISSN 0066-5061.
} 
bienes de los ceramistas y vidrieros de los siglos XV al XVII, aunque se centra sobre todo en el siglo XVI, debido a que la mayor parte del material localizado pertenece a esta etapa. Incluye tanto documentos correspondientes a estos artesanos como a sus esposas, siempre que el traspaso de la herencia y el inventario de éstas se hubiese realizado sin contraer un segundo matrimonio, pues entre los objetivos perseguidos se encuentra llegar a saber como vivían los citados artesanos. Es decir, poder conocer algunos de los objetos que empleaban habitualmente También se quiere obtener una noción de su modo de vestir, costumbres y aficiones, así como de los útiles de cerámica y de vidrio que se podían encontrar en sus viviendas. Finalmente se efectúa un análisis de los obradores y tiendas a través del cual se puede establecer un balance no sólo de los utensilios que tenían en el taller, sino del tipo de producción que llevaban a cabo. En concreto los apartados son los siguientes: 1) Los objetos de uso personal (los juguetes de los hijos, los rosarios y libros religiosos, las armas, los juegos y otras pertenencias que muestran su modo de vida y costumbres), 2) Los vestidos, las joyas y los objetos curiosos; 3) Los objetos de cerámica; 4) Los objetos de vidrio; 5) El obrador y la tienda; 6) Los precios y valores de algunos objetos.

Se han utilizado los inventarios y subastas de los artesanos que se indican a continuación, si bien de las mencionadas subastas únicamente se han seleccionado aquellos bienes relacionados con el mundo del arte y de la artesanía; excluyéndose los que tenían que ver con el coste de los productos de la vida diaria, pues carecen de interés en este estudio. En cambio si que se han obtenido algunos precios de obras elaboradas por los mismos. Entre los ceramistas se hallaban: los jarreros: Bernat Marquès $(1489)^{2}$ y Pau Miralles (s. XVII) ${ }^{3}$; los escudilleros: Joan Codina $(1527)^{4}$, Antoni Rosell $(1547)^{5}$, un escudillero anónimo $(1563)^{6}$, Bartomeu Espasa $(1595)^{7}$, Pere Bonarres sueltos.

${ }^{2}$ Arxiu Històric de la Ciutat de Barcelona, Arxiu Notarial III, nº 2, años 1480-1489, 4 fols

${ }^{3} \mathrm{AHCB}$, Arx. Not. I, $\mathrm{n}^{\circ} 46$, siglo XVII, 3 fols.

${ }^{4} \mathrm{AHCB}$, Arx. Not. I, $\mathrm{n}^{\circ} 28$, año 1527, 12 fols.

${ }^{5} \mathrm{AHCB}$, Arx. Not.I, $\mathrm{n}^{\circ}$ 32, año 1547,8 fols.

${ }^{6} \mathrm{AHCB}$, Arx. Not. I, n⿳0 35, año 1563, 6 fols.

${ }^{7} \mathrm{AHCB}$, Arx. Not. I, $\mathrm{n}^{\circ} 45$, año 1595,9 fols.

«Anuario de Estudios Medievales», 34/1 (2004), pp. 307-355.- ISSN 0066-5061. 
$(1598)^{8}$, Marià (s. XVII) $)^{9}$ y los ladrilleros: Antoni Calbus $(1544)^{10}$ y Pau Figueres $(1598)^{11}$. Las esposas de los escudilleros: Eufrasina Serdana $(1525)^{12}$, mujer de Joan Serdà; Elisabeth Bramona $(1584)^{13}$, viuda de Joan Bramona; Magdalena que se había casado con Pere Bonarres (1598); Francisca (1471) esposada con el ladrillero Sancho ${ }^{14}$, al igual que Joana Baltasar mujer del ladrillero Antoni Baltasar $(1584)^{15}$. La mayor parte de los textos, en total 14 (10 de profesionales y 4 de esposas) pertenecen al siglo XVI. Existe un documento de un jarrero (Bernat Marquès) de fines del siglo $\mathrm{XV}$, junto a dos inventarios del siglo XVII: el del jarrero Pau Miralles y el del escudillero Marià.

En cuanto a los vidrieros, disponemos de 5 documentos ( 3 de artesanos del vidrio, 1 correspondiente a una viuda y 1 de un mercader de vidrio). Dos pertenecen al siglo XV y los otros tres forman parte del siglo XVI. Los vidrieros son: Joan Llorenç $(1451)^{16}$, Joan Barragó $(1577)^{17}$, Jacob Monbopés $(1588)^{18}$, la viuda, cuyo nombre era Valença, se había casado con Bernat de Mont (1412) ${ }^{19}$ y el mercader de vidrio se llamaba Joan Benet Puig $(1506)^{20}$. Cabe señalar que existía una notable diferencia entre los bienes del último, en cuanto a variedad y cantidad, con respecto a los tres vidrieros, lo cual nos sugiere que su posición social era mejor.

A pesar de que la información con que contamos no es excesivamente amplia, se ha establecido una diferenciación dentro de cada apartado entre ceramistas y vidrieros, que nos permita llevar a cabo una valoración más clara

${ }^{8}$ AHCB, Arx. Not. I, $\mathrm{n}^{\circ} 46$, año 1598,8 fols.

${ }^{9} \mathrm{AHCB}$, Arx. Not. I, $\mathrm{n}^{\circ} 46$, s. XVII, 3 fols.

${ }^{10} \mathrm{AHCB}$, Arx. Not. I, $\mathrm{n}^{\circ} 31$, año 1544, 6 fols.

${ }^{11}$ AHCB, Arx. Not. I, no 46, año 1593, 9 fols.

${ }^{12}$ AHCB, Arx. Not. III, $n^{\circ} 4$, años 1525-1529, 8 fols.

${ }^{13} \mathrm{AHCB}$, Arx. Not. I, $\mathrm{n}^{\mathrm{o}} 10$, año 1584, 6 fols.

${ }^{14} \mathrm{AHCB}$, Arx. Not. I, $\mathrm{n}^{\mathrm{o}} 12$, año 1471, 4 fols.

${ }^{15}$ AHCB, Arx. Not. I, $n^{\circ} 40$, año 1584, 3 fols.

${ }^{16} \mathrm{AHCB}$, Arx. Not. I $\mathrm{n}^{\circ}$ 9, año 1451, 11 fols.

${ }^{17} \mathrm{~A}, \mathrm{CB}$, Arx. Not. IX, $\mathrm{n}^{\mathrm{o}}$ 6, año 1577, 6 fols.

18 U. Arx. Not. I, $\mathrm{n}^{\circ} 41$, año 1588, 4 fols.

${ }^{19} \mathrm{AHCB}$, Arx. Not. I, no 4 , año 1412, 21 fols.

${ }^{20} \mathrm{AHCB}$, Arx. Not. I, $\mathrm{n}^{\circ} 22$, año 1506,10 fols. 
e independiente de cada sector, a pesar de que existen elementos comunes entre ambos grupos. Así se podrá delimitar cada ámbito profesional. Igualmente los aspectos que tienen que ver con los productos y costes de los mismos se analizarán, por separado, tras la descripción de los caracteres de los talleres respectivos.

\section{LOS OBJETOS DE USO PERSONAL}

Los objetos que tenían en sus casas y las propiedades eran escasos y mucho más diversos que en la actualidad, en el sentido de que cada uno no lo poseía todo, ni los útiles eran los mismos en todos los domicilios. Si uno contaba con un martillo, otro había comprado un espejo, otro un peine, etc.... Exceptuando los utensilios casi imprescindibles de cocina y de ajuar doméstico que aparecen en casi todos los inventarios, y de algunos productos o piezas que se introducían por vía de la importación, tales como alfombras o telas de un país o zona, y que se localizaban en algunas viviendas. Además, muchos de estos artesanos elaboraban los productos de consumo propio tales como el pan, $u$ otros alimentos o bien los obtenían mediante el desarrollo de tareas agrícolas. Igualmente ocurría con la ropa de casa y los vestidos; unos compraban la tela hecha, pero algunos se tejían y confeccionaban las sábanas y trapos de cocina, e incluso sus vestimentas personales.

Los juegos y objetos infantiles. Se han localizado en las viviendas de los ceramistas pequeños objetos de barro cocido: ollitas, platos, soperas, etc. ("fireta") que servían para los juegos infantiles, probablemente de las niñas. Cada juego constaba de una serie de piezas. En casa de Bartomeu Espasa había 8 juegos y es muy probable que no todos fueran para sus hijos, sino que alguno se hallara destinado a la venta. También Margarita Bonarres contaba con algunas piezas de estas características que se hallaban en la cocina de su domicilio.

Asimismo, se han encontrado muebles destinados a los niños, un cajón ("guixeta") de criatura, o bien ropa guardada, no siempre en buen estado, y una piel para cubrirlos (la mayor parte de estas piezas se localizaron en casa de Margarida Bonarres).

En cuanto a los objetos de vidrio no se empleaban como juguete. No los hay para tal fin ni en las viviendas de ceramistas, ni en las de vidrieros. Los últimos, también disponían de juguetes infantiles, aunque no se especifica 
como eran éstos a través de los datos obtenidos. En el inventario de Joan Llorenç, por ejemplo, se indica que figuraban: "Joguines de infant ab una branqueta de coral" (es posible que emplearan el coral como un juguete, o bien como un adorno del mismo). Además en casa de Joan Benet Puig se guardaban dos cubrecamas ("Vanonetes petites per bolcar") empleados para poner el niño encima. Existían, por consiguiente, toda una serie de productos destinados a éstos, tales como una cama infantil de madera ("brasol ab pues gran de fusta dalber").

Los rosarios, libros religiosos y capillas. A pesar de que éstos objetos no se hallaban de un modo generalizado en todas las viviendas, era habitual encontrarlos entre sus bienes, debido al grado de religiosidad y espiritualidad existente, aunque estas prácticas no eran propias de todas las personas. Así por ejemplo, algunos desarrollaban penitencias exageradas, pues en una de las casas correspondiente a un ceramista hemos hallado unos hierros para disciplinar el cuerpo y hacer penitencia ("unes dexeplines" tenía Margarida Bonarres). En los domicilios del mismo grupo de artesanos se han encontrado "saltiris o salteris" (salterios), nombre que recibían los precedentes del rosario. Los había de coral, o ámbar, materiales con los cuales se elaboraban; también se describían destacando su tonalidad: "de malva", y a veces los guardaban dentro de cajas. Igualmente sus dimensiones no eran siempre las mismas ("de cambres molt petites"). Hemos encontrado salterios únicamente en dos domicilios: el de Antoni Rosell y el de Elisabeth Bramona, si bien cada uno de éstos contaba con varios; en cambio, en ninguna casa consta que hubiese un libro de doctrina. En cuanto a los vidrieros se refiere, ocurre un fenómeno similar. Tenían algún "parenostra" (o rosario), en este caso se halla denominado por su función, pues lo empleaban para el rezo de tal oración en las viviendas de Joan Llorenç y de Valença de Mont. Llorenç tenía uno de coral y otro de paño negro (realizado con telas atadas y nudos) y los de Mont se hallaban situados en la habitación. Sabemos que los rosarios, también eran designados con el nombre de "rastre". Estos objetos se creaban a partir de los materiales más insólitos: huesos de aceituna; bolas de madera, vidrio, cerámica, además de los materiales mencionados antes. Curiosamente, Valença de Mont guardaba algunas oraciones dentro de frascos, pero es muy posible que se tratara de una especie de símbolo protector. El único que probablemente había aprendido a leer era Joan Benet Puig, comerciante de vidrio, pues conservaba un doctrinal en pergaminos o libro de catequesis. Los demás libros localizados servían para anotar las cuentas, y por lo tanto se 
hallaban destinados a fines comerciales de compra-venta, pero a través de éstos se reflejaban los conocimientos de números y cuentas que tenía su propietario, y tal vez alguna noción de escritura; además en los localizados en casa de Joan Llorenç se había incluido un texto que decía "Nostra Senyor Deu sia baneyt" (es decir, "Dios nos bendiga"), probablemente la frase escrita allí tenía una finalidad protectora orientada a obtener fortuna en los negocios.

Recordemos que tanto en las viviendas de ceramistas como en las de vidrieros había también capillas, normalmente de madera, con escenas de la vida de Cristo, la Virgen y los santos, tales como: la salutación del ángel a María, la Virgen con el niño Jesús en brazos y algunos corderos, un crucifijo con las Marías, la pasión de Cristo, los cuatro evangelistas, el Corpus Cristi, Ntra. Sra. del Rosario. Algunas de las figuras internas eran de terracota, pero se habían incluido a veces dibujos de tema religioso dentro de la misma, en lugar de esculturas. Existe un detalle curioso y es que el vidriero Joan Llorenç tenía una capilla de papel. Las de madera podían llevar algún cristal protector. Este asunto ha sido tratado con más detalle en otro trabajo ${ }^{21}$.

Otras escrituras y albaranes. Si bien no todos guardaban escrituras en sus domicilios, era común hallarlas. Las más corrientes eran los capítulos matrimoniales (Elisabeth Bramona), unos censales, apocas y otros papeles de índole legal (Valença de Mont y Joan Benet Puig).

En cuanto a los albaranes o libros de cuentas, sólo los hemos encontrado en el domicilio de los ceramistas: Joan Codina y Joan Bramona y había varios en casa del vidriero Joan Llorenç, los cuales ya se han mencionado. Uno de ellos se hallaba formado por una cubierta de cuero rojo y un cierre, las hojas sueltas y en la primera página, se observaba un título escrito en letra roja y el texto se había redactado en tinta negra. Este artesano tenía libros de cuentas anuales con las entradas y salidas, y en casa del mercader de vidrio Joan Benet Puig, se encontraban algunos papeles o albaranes.

Las armas se hallaban en casi todas las viviendas, y se utilizaban no sólo para la caza, sino como un medio de defensa en caso de guerra. Éstas les venían asignadas y la posesión de unas u otras dependía muchas veces de su nivel adquisitivo. En los inventarios de ceramistas se han localizado las

\footnotetext{
${ }^{21} \mathrm{C}$. RIU DE MARTÍN, El patrimonio de ceramistas y vidrieros barceloneses. Aspectos socioeconomicos (s. XV-XVII), en "Estudis i Documents dels arxius de protocols" (Col.legi de Notàris de Catalunya. Barcelona), XXII (2004) (en prensa).

«Anuario de Estudios Medievales», 34/1 (2004), pp. 307-355.- ISSN 0066-5061.
} 
siguientes: 1) el arcabuz, de cuatro palmos o de cinco, con su guarnición o frasco (para depositar la pólvora). Éste podía presentar un buen o mal estado de conservación, y aparece mencionado en los domicilios de: Margarida Bonarres, Bartomeu Espasa, Antoni Calbus, Pau Miralles y un escudillero anónimo. Era el precedente de la escopeta. 2) La escopeta, un poco posterior se empleaba también para la caza. Tenía una Bartomeu Espasa. 3) El mosquetón, con su frasco y sus horquillas ("sos flascos y forquelles"), se encontraba en el inventario de Marià y correspondía ya al siglo XVII. 3) La espada, era un arma muy frecuente y la describían con o sin vaina, y en buen o mal estado. Podía ser de estilo antiguo, o con acabados redondos (un escudillero anónimo). Normalmente sólo tenían una (Pau Miralles, Margarida Bonarres, un escudillero anónimo, Antoni Cabus), pero podían guardar otra como prenda por un préstamo; así ocurre con Joan Codina. 4) La daga (o espada corta) diseñada imitando el método antiguo de envainar se hallaba en poder de Bartomeu Espasa. 4) La ballesta, con algunas flechas era menos común que la espada o el arcabuz. Contaba con una Antoni Rosell. 5) La lanza, la pica y la alabarda también pertenecían a Antoni Rosell. 6) La palanca (o "manovina"), tal vez empleada como arma, y la caja de guardarla eran propiedad de un escudillero anónimo. 7) Una "coltelina" o "coltell" (cuchillo delgado), ubicado en el inventario entre las armas, aunque podía estar destinada a otros usos (formaba parte del documento correspondiente a un escudillero anónimo). 8) Las rodelas (podían tratarse de escudos pintados para proteger el cuerpo, sobre todo si en el texto aparecían junto a las armas). Vemos, pues, que los artesanos que se hallaban en poder de más de una arma, la segunda y siguientes eran de carácter muy diverso a la primera, pues no solían guardar dos similares.

También abundaban las armas entre los vidrieros, e incluso las armaduras, En cuanto a las armas: La espada (Joan Llorenç y Jacob Monbopés. El primero conservaba dos, pero una de ellas se encontraba en mal estado y la de Monbopés presentaba un bruñido y dorados en su superficie, siendo su asa negra y se completaba con una vaína), la ballesta (Joan Llorenç la tenía de acero, con un "martinet" o hierro y un asa para tensarla, y Joan Benet Puig del tipo conocido bajo el nombre de "senal"). La daga, más gruesa, se hallaba en propiedad de Jacop Monbopés. Además, se observan otras piezas distintas: una lanza (usada para poner la bandera), un dardo y su punta, junto a un puñal con sus vainas. Y como complemento se usaba la "servellera" o pieza de la armadura para poner bajo el casco (tanto Jacob Llorenç, como Joan Benet Puig empleaban una, y parece que ambos eran 
aficionados a las armas, pues poseían varias) y el "carcaix" o "aljane", las últimas eran una especie de bolsas de cuero con pasadores que servían para poner las flechas dentro, probablemente de la ballesta, pues las de arco ya no se utilizaban. Además no se comenta la existencia de ningún arco en los textos revisados ${ }^{22}$.

La caza y el juego. La primera se trataba de una de las aficiones más practicadas, aunque no de un modo generalizado entre estos artesanos. Encontramos un ceramista, Bartomeu Espasa que guardaba: 3 redes de hilo para cazar conejos, unas esferas, palos y ganchos ("bordons, verges y gansos") de hierro y una escopeta larga. Todos estos útiles servían para la caza. Igualmente en su casa se guardaba una mesa redonda terciada con un juego de ajedrez en el centro. Otro juego corriente en la época, si bien sólo practicado por este artesano en cuanto al sector estudiado se refiere.

Las actividades usuales. Se trata de una serie de tareas que efectuaban gran parte de ellos tanto los ceramistas como los vidrieros, tales como labrar la tierra, poseer animales de granja (gallinas) u de otro tipo: bueyes, asnos, burros o caballos para el transporte de objetos y las tareas del campo. Contaban con varios arreos empleados para tales fines: alforjas, capazos de fibra vegetal, arneses, serones, etc... junto a alguna carreta (el ceramista Pau Figueres tenía una). Los animales se hallaban en función del desarrollo de tareas, así por ejemplo, el mercader de vidrio contaba con un burro, dos asnos, uno para el servicio doméstico y dos bueyes para las actividades agrícolas. En cuanto a los trabajos agrícolas, se basaban en la tenencia de huertos, en la parte posterior de la casa o en sus proximidades, y campos de cultivo de cereales y viñas, que les permitían abastecerse en parte. Para más detalles se puede consultar el trabajo anteriormente $\operatorname{citado}^{23}$, al igual que para ampliar los aspectos relacionados con la manufactura de tejidos.

En sus viviendas se han localizado tornos de hilar lana, telares y otros elementos para confeccionar telas: devanaderas, peines, husos, etc.. para tejer hilo de estopa, cáñamo, mezcla de cáñamo y estopa, algodón, lino sólo o mezclado con estopa, lana, a través de las cuales la esposa efectuaba ropa de

\footnotetext{
${ }^{22}$ M. DE RIQUER, L'arnès del cavaller. Armes $i$ armadures catalanes medievals, Barcelona, Ed. Ariel, 1968, 237 p

${ }^{23}$ C. RIU DE MARTÍN, Ob.cit.
}

«Anuario de Estudios Medievales», 34/1 (2004), pp. 307-355.- ISSN 0066-5061. 
la casa y de uso personal. Asimismo, compraban tejidos de importación de Chalons, Courtray, Brujas, Damasco, Alejandría y de Benjuy, entre otros, pues las citadas poblaciones aparecen mencionadas en estos documentos. Junto a alfombras, cojines y otros objetos de importación. Así, el mercader de vidrio Joan Benet Puig se hallaba en poder de un paño de ruso grande con figuras de Tournai (localidad de Flandes) y algunos frutos, y el vidriero Joan Llorenç contaba con una tela negra forrada de Damasco, por citar algún caso.

\section{LOS VESTIDOS, LAS JOYAS Y LOS OBJETOS CURIOSOS}

En cuanto a la indumentaria, existen una serie de prendas estrictamente masculinas, otras femeninas y otras de uso indistinto. También se han encontrado algunos vestidos infantiles.

Prendas masculinas. En cuanto a los ceramistas tenían: zapatos, abarcas ("abares" o zuecos) y pantuflas ("plantofles"), junto a sombreros de hombre, uno era negro, y de otro se indica que su calidad era buena y se hallaba forrado, y además consta otro negro, que pertenecían respectivamente a Pau Miralles y Joan Codina. Éstos junto a los mantones (de estambre o "stam bo", un tipo de tela), los mantos (o "mantells") y las capas con capucha o "capus" ("de Contray" o Courtray una población de Flandes) se empleaban con regularidad, hallándose las últimas prendas mucho más generalizadas que las dos anteriores, pues éstas formaban parte a veces también del vestuario femenino y se comentarán posteriormente al tratar el tema.

Los jubones ("gipons" eran prendas o cuerpos que aunque solían llevar mangas se asemejaban a los chalecos y los había de terciopelo negro, de lana, de algodón ("cotonyna") blanco o leonado (o amarillento), pudiendo combinarse un material para el cuerpo y otro para las mangas. Por ejemplo podían ser de orlanda con las mangas de tafetán ("tafeta"). Los había de importación: jubón de Damasco negro (pertenecía a Joan Codina), de "Fustany" o Al-Fustat (originariamente de Egipto) de tono negro o castaño ("pardilo") - Su estado de conservación y tonalidades eran variadas; además esta tela de algodón en esta época se elaboraba en Barcelona y otras localidades.

En ocasiones llevaban casacas. Entre las mencionadas destaca la descripción de una perteneciente a Pere Bonarres: "una casaca de xamallot so es bona ab manegues de tafeta dolentas". Vemos que consiste en una casaca con mangas de un tipo de algodón especial, con el cuerpo de "Xaló" o 
"Txalon" (Chalons, una población del norte de Francia) y las mangas de tafetán. Probablemente ésta hacía juego con unas calzas ("calsots") de "Xaló" falso usadas. Además Pau Figueras contaba con un conjunto formado por calzas y casaca con mangas también y otro de "stamenya" ("estamenya o stemenya", tejido de lana ordinario fabricado en Banyoles y Ripoll entre otros lugares) con las mangas de "Xaló" negro. Existían algunas variantes en la combinación del tejido del cuerpo y las mangas de la casaca y calzas, pudiéndose cambiar también los colores de una y otra parte. Pues entre las calzas citadas hemos hallado unas de tela de "stamenya" y otras de "cordellat". Curiosamente, se han encontrado dos calzonzillos ("calsotets") de lino, ambos pertenecientes a Pere Bonarres, aunque esta prenda apenas aparece citada en los inventarios, únicamente vuelve a surgir en el de Pau Miralles, y según se expone allí, los mismos se hallaban en muy mal estado.

Finalmente, empleaban camisas de diversa índole. En ocasiones en un mismo documento se han llegado a contar 12 ejemplares (Pau Figueres), 8 piezas (Bartomeu Espasa), 7 (Pere Bonarres) 6 ( Pau Miralles), 5 (Joan Codina) y 2 (Antoni Calbus). Las camisas eran de paño casero (probablemente elaboradas en el telar familiar, como ocurría con las de Joan Codina, Antoni Calbus o Bartomeu Espasa). En el caso de Pere Bonarres, Pau Miralles no sabemos si eran de confección casera y las de Pau Figueres habían sido confeccionadas con "bri" de lino y de cáñamo. Su estado de conservación era diverso, pero mientras Pau Figueres iba descuidado y con camisas en mal estado, las de Joan Codina o Pau Miralles eran muy nuevas, y el resto guardaba piezas en buen y mal estado.

Por su parte los vidrieros llevaban trajes semejantes. Como nota curiosa a destacar Jacob Monbopés iba vestido de payés, pues contaba con una barretina, una faja y una correa, aunque era el único que tenía también un sombrero de fieltro. Igualmente poseía una "scarcela" o pequeño monedero para colgar en el cinturón de cuero, con hierros y un arito para cerrarlo; siendo también propietario de 3 bufandas. Jacob Monbopés murió sin dejar familia y de mayor vivía en casa de unos taberneros, por lo tanto, es muy probable que la bolsa descrita fuera suya y no de una mujer,

Otra prenda común era la capa con capucha ("barreta") oscura, y el mantón con capucha ("clotxe") de trapo de "bruneta", ambas de Joan Llorenç. Los cuerpos de jubón podían ser de confección casera, con un tejido de calidad barata (Jacob Monbopés), o de compra : de "Fustany" negro con media manga de trapo oscuro (Joan Llorenç), de "Fustany" rojo con unas mangas oscuras en las que se combinaba el trapo y el terciopelo (de Joan 
Llorenç y era nuevo), o de "Fustany" leonado, también con media manga distinta pero traída de "Fustany" (Joan Benet Puig) y las casacas. Las últimas no eran muy corrientes, pero Jacob Monbopés tenía una de burel ("burell"), y una de lana sencilla, en mal estado.

Entre las camisas se encuentran: 2 de color rojo de "cordellat" -probablemente un tipo de ropa-(Jacob Monbopés), 4 piezas - dos nuevas y dos usadas-, sin especificar más (Joan Llorenc), y algunas finas o "sotils" (Joan Benet Puig).

El calzado más frecuentemente usado eran los zapatos (Jacob Monbopés poseía un juego y Joan Llorenç otro), además habían las "bassases" (o polainas) de cuero, que consistían en un tipo de media que se enrollaba a los pies y piernas para protegerlas, por ejemplo éstas se empleaban para ir a cazar (las descritas eran propiedad de Joan Llorenç) ${ }^{24}$.

Prendas femeninas. Entre las mismas se encontraban algunas que pertenecían a esposas de ceramistas como el jubón. Pero únicamente aparecen en el inventario de Pau Figueres uno de tafetán negro en buen estado y otros dos de satén, uno negro y otro leonado ambos usados, lo cual nos lleva a considerar que no era corriente la utilización femenina de la prenda. Ni tampoco la del sayo, el cual aparece con la denominación "sayet" negro usado en el texto de Eufrasina Serdana, pues debía ser de una talla pequeña.

El empleo de vestidos en cambio era un poco más común, hallamos algunos negros, uno de tela de satén vieja ("desatinat". Marià lo guardaba), pero el elemento más usual eran las faldas. Las había de lana, de tafetán (un tipo de ropa ensedada), de algodón, aunque en muchos casos se describen teniendo en cuenta su color: rojas, moradas con un friso en la parte inferior, de color de asno (así constan descritas, por ser probablemente de un tono grisáceo), azules, negras, naranjas, granates con dos franjas ("dos viuets"), o rojas con guarniciones de terciopelo. El color rojo debía ser muy normal pues aparece en cuatro ocasiones. Casi nunca se indica si tenían estampados, pero en cambio se alude al estado de conservación en que se hallaban y podían incluso haber sido formadas mediante retazos ("padassos". Joana Baltasar tenía dos con tales características, al igual que Francisca Sanxo, que había obtenido otras). Igualmente algunas eran de tela importada: de Cádiz (Antoni Rosell) o de Vernay (Eufrasina Serdana). La combinación de tonos entre la

\footnotetext{
${ }^{24} \mathrm{M}$. Gual Camarena, Vocabulario del comercio medieval, Tarragona, Publicaciones de la Diputación Provincial, 1968, 531 p.

«Anuario de Estudios Medievales», 34/1 (2004), pp. 307-355.- ISSN 0066-5061
} 
falda y el cuerpo se daba a menudo: "unes faldilles blaves ab cos d.asa ab les manegues d.agulla vermelles" (es decir: falda azul y cuerpo grisáceo con las mangas acampanadas rojas, de Joana Baltasar). Asimismo, se ha hallado una ropa delgada de mujer (Francisca Sanxo), de la cual no se especifican más características, un traje de novia ("teles de casar", de un escudillero anónimo), y un vestido de monja ("un mongil") de "stamenya" de Reus (perteneciente a Antoni Rosell).

El "brial" (definida como una túnica con mangas estrecha) podía ser de "xemellot" (un tipo de algodón, como se ha dicho), de algodón ("cotonina") o de sayal (o tela usual). Vemos que había diversas denominaciones para el tejido de algodón, probablemente debidas a sus características específicas. Además, los dos últimos tipos de tela se empleaban con mayor frecuencia. Normalmente su color era negro o blanco, aunque también podían tener rayas ("verguas"), o bien llevar un forro de tela leonada (como el del inventario de Joan Codina); presentando un buen o mal estado de conservación. La "gonella" consistía en el término que recibía una especie de chaqueta, que únicamente surge en el inventario de Francisca Sanxo (pura o típica y delgada, pero con retazos). Había también algunos mantones (el tradicional o el escotado; en una ocasión de "stamenya") y capas ("capot" o "capella"). Una piel de ciervo ("venable"), y mangas sueltas ("tres parells de manegues de sati negres", "un parell de manegues de tafeta negra usades", ambas de Pau Figueras).

En cuanto a los complementos cabe prestar atención a: las bufandas finas ("balones") o velos, que podían ser de luto (Margarida Bonarres poseía uno); ambas eran prendas muy usadas (Pau Figueres guardaba 4 piezas), el cinturón ("sinyell", de Joana Baltasar), los sombreros ("sombrero" o "capell", muchas mujeres tenían uno y aunque apenas aparecen descritos sabemos que tanto podían ser negros, como de algún color), una beatilla (de Antoni Calbus) y un pañuelo de tela (normalmente éstos servían para sonarse la nariz. Elisabeth Bramona guardaba uno) y unos zapatos (de Margarida Bonarres).

La ropa interior se hallaba formada por: el corsé o corpiño ("un cos blanc", "cossets", "conserts", "cosos de cotonina de casa"). Éstos podían llevar mangas y "bots" (botones u otro sistema de cierre), las bragas (denominadas con los siguientes términos "calses de cordellat", "femoral", "braguer") podían ser de colores, pues la mujer de Antoni Calbus tenía unas rojas, y las había también con un montante para atarlas. Algunas llevaban también faldones ("faldons" o "sota de dona"), normalmente viejos o muy 
usados, de tela mezclada y en un caso hemos encontrado unos de "Fustany", si bien se indica que los últimos eran vulgares. Y las fajas de algodón blanco o de terciopelo rojo (de Margarida Bonarres), las medias (la mujer de Marià y Margarida Bonarres) y curiosamente unas ligas, prenda que sólo surge mencionada en una ocasión ("unes lligas de rosa de tafeta negra ab puntilla de plata", correspondientes a la mujer de Marià), completaban el vestuario.

Finalmente, las camisas para dormir de tejido realizado en casa o de "bri" de cáñamo, solían ser bastante comunes. Joana Baltasar tenía "unes camises de lligar". Éstos conservaban gorras para dormir ("bonets") y peucos ("pouls"). Ambos complementos pertenecían a Francisca Sanxo. Aunque no hallaban en general estas prendas muy desgastadas, la mayor parte ya habían sido estrenadas y formaban parte del vestuario habitual. Cabe recordar que o bien los inventarios omitían detalles sobre las ropas, o no todos los hombres, ni mujeres contaban con los juegos de vestir completos. Como detalle original en casa de Margarida Bonarres se guardaba la ropa en un cesto: "un covenet ab unes sabates i mijes de dona y altra robeta de la minyona" (pudiendo ser "la minyona" tanto la hija como la criada) y no en los baules.

Veamos la ropa correspondiente a las mujeres de vidrieros. Ésta se hallaba compuesta por: la "gonella" (o chaqueta oscura, blanca o morada. Valença de Mont tenía una forrada de pieles blancas), la gramalla (vestido hasta los pies, que solía ser de hombre, salvo excepciones. Hemos hallado una negra forrada de piel de conejo (también de Valença de Mont) y los mantos podían ser de "bruneta" (un tipo de ropa), o bien de Courtray (una localidad de Flandes. El último correspondía a la esposa de Joan Benet Puig) y normalmente eran de tonos oscuros o negros. Hemos hallado bastantes ejemplares de manto. Las capas definidas como "rollo de drap", podían llevar aplicaciones; así la de Valença de Mont mostraba unas pieles negras en las mangas.

En cuanto a los complementos, se empleaban las toquillas (Joan Monbopés), los pañuelos ("captís" de luto por ser negro), también denominados velos y que podían ser de lino, o más o menos gruesos (los de verano se llamaban "estivales"), y las capuchas (las que se hallaban en poder de Joan Llorenç eran blancuzcas). Se encontró una ropa para el parto ("drap de partera"), con tres personajes dibujados y que se hallaba forrada de tela leonada procedente de Tournai (una ciudad de Flandes; pieza que correspondía a la mujer de Joan Benet Puig). Otra tela importada de Damasco, de "bruneta" oscura, era propiedad de Joan Llorenç. 
Y cabe destacar entre la ropa interior: las calzas de Flandes (Joan Llorenç), las de lino (Jacob Monbopés, quién probablemente debió estar casado), una especie de corpiño ("cota") de ropa de Bagà (también de Valença de Mont) y unos camisones (para dormir) alguno de lino y de los demás no se especifica el tipo de tejido. Las descripciones de los objetos documentados, se efectúan teniendo en cuenta las características de la tela, el color, el estado de conservación, el lugar de procedencia del tejido o algún carácter distintivo. En el caso de las mujeres de los vidrieros, no aparecen mencionadas prendas tales como los vestidos o faldas, lo cual resulta un tanto extraño, ni tampoco los zapatos.

Prendas infantiles. Apenas se comenta en los inventarios la existencia de tales vestidos: el ceramista Bartomeu Espasa guardaba dentro de una caja una ropa de criatura muy vieja, pero no se describen sus características; el vidriero Jacob Monbopés un conjunto infantil formado por calzas, casaca de burel y unas medias a juego. El mercader de vidrio Joan Benet Puig contaba con dos piezas; aunque no se especifica cómo eran, el tejido de algodón nos lleva a deducir que se empleaban en verano ("cosetes petites d'infant poch de cotonyna").

Prendas usadas por ambos sexos, de las cuales resulta difícil llegar a saber a quién pertenecían, porque no se precisa tal aspecto. Entre las ropas curiosas propiedad de algunos ceramistas, se hallaban las nazarenas ("natzerenas", unas túnicas con capucha) que servían para enterrarlos y probablemente las usaban en las procesiones. Las había de diversos tipos aunque todas ellas llevaban guarniciones o acabados de terciopelo: de raso ("raxe", Margarida Bonarres), de tafetán negro (Pau Figueres), o con cuello ("gorgera") y sin indicar la tela de la cual habían sido elaboradas (también de Pau Figueres).

Se ha localizado una rodillera ("rodillota") en mal estado, de Bartomeu Espasa, de la que desconocemos su uso exacto, pues no se sabe si era preventiva, o bien se empleaba en caso de lesión. Entre los objetos de complemento se da noticia de: una bolsa de cuero corriente (la llevaba "un escudillero anónimo" para depositar el dinero), otra bolsa también de cuero iba agarrada a un cinturón (Joan Codina) y un cinturón nuevo (Margarida Bonarres). Varios sombreros (2 de Margarida Bonarres y 1 que se hallaba forrado de tafetán y pertenecía a Pau Figueres), numerosas bufandas denominadas "torquaboques", "tapaboques", "sotaboques", "torcaboques" 
y otros nombres similares. En algunos domicilios había muchas: 28 (Margarida Bonarres), 15 (Bartomeu Espasa), 13 (un escudillero anónimo), 12 (Joana Baltasar y Joan Codina), 7 (Pau Miralles), 6 (Antoni Calbus), 4 (Antoni Rosell), 3 (también de Bartomeu Espasa, y otras 2) y un tejido de 10 o 12 canas (de Pau Figueres). Las descripciones nos permiten concluir que eran unas piezas de uso muy común, que las había de tamaño grande y mediano y también que podían haber sido confeccionadas con estopa, o con mezcla de hilo y algodón; algunas presentaban "escacats" o "scacts" , es decir cuadraditos, por tanto debían ser de cuadros; aunque no se indica el color de las mismas, si que se menciona el estado de conservación. Unos zapatos (Margarida Bonarres) y unas botas blancas (un escudillero anónimo) se encuentran como prendas raras.

En cuanto a la ropa interior apenas se cita: una medias de "stamenya" que tanto podían ser masculinas como femeninas, pues eran usadas por ambos sexos, al igual que unas calzas ("calses") de "cordellat" negro con un forro blanco, un braguero y un montante para atar las bragas. Entre las ropas que servían para acostarse se hallaban las camisas de uso corriente, aunque no todos las empleaban. En el inventario de Marià, se indica el tipo de tejido, cáñamo ("canem"), en que habían sido elaboradas.

Igualmente entre las prendas de vestir comunes se daba: la "gonella" (una especie de túnica usada indistintamente por hombres y mujeres). Se indicaba su tela: lana, o se hacía referencia al color: granate casi siempre, aunque también podía ser azul, violeta o marrón. Las que iban forradas, llevaban un forro azul y curiosamente, Eufrasina Serdana tenía varias que habían sido guardadas como prenda. El sayo, "saya" o "sayet" (un diminutivo) era también empleado indistintamente por ambos sexos y los había de trapo "ginjol", de borel ("borell"), de lana, de mezcla, etc., con o sin mangas (probablemente según la estación del año), podía estar forrado (de tono verde, amarillo), y a veces, incluía detalles en terciopelo. Los había de importación, procedentes de Countray (Joan Codina y Antoni Rosell), también de estilo antiguo, su tono podía ser el saya o color hueso, el amarillo (Antoni Rosell) y podían incorporar pieles de rata por ejemplo (Antoni Rosell). A destacar una pieza de Antoni Calbus: "un sayet de saya ab manega brodada ab sa porta ab mostres de vellut a les manegues ben usat". De todos modos las guarniciones que se repartían encima de la superficie con mayor normalidad, se efectuaban usando terciopelo. En un cofre (en casa de Joan Codina) se había depositado una ropa de saya negra con aplicaciones de terciopelo negro probablemente pertenecientes a una chaqueta, o con el objetivo de confeccionar una nueva. 
Para completar se cubrían con los mantos ("mantell") de "barata" (un tipo de ropa) con aplicaciones de tafetán, de "stamenya" y seda, o bien de seda y detalles de terciopelo. Casi todos ellos tenían uno que usaban a modo de abrigo, o bien una capa. en su lugar. Antoni Calbus poseía "un mantell de scot dolent" y Joan Codina uno de Cadiz negro adornado con siete rayas de terciopelo negro también. Las capas ("capa", "capot", "capota") tenían diversos usos que se especifican a menudo: podían ser de luto (Margarida Bonarres), para la lluvia ("daigua de burell ja usada". Joan Codina), de pastor (Bartomeu Espasa contaba con una blanca de lana, probablemente adecuada para vigilar el ganado), o para cubrirse simplemente. Las había de fieltro con acanaladuras blancas, grises con guarniciones de terciopelo oscuro ("pardilo"). Se han localizado bastantes, y se sabe que era una prenda empleada con frecuencia por las personas pobres.

De los vidrieros poseemos menos información. Un objeto distinto a los anteriormente mencionados eran los pañuelos (cuyo uso podía ser para sonarse, o bien para cubrir la cabeza de las mujeres casadas). Por las descripciones sabemos que podían llevar "fusells" (pequeños husos), "fusells i nuets" (husos y nudos), "brodat de fil rovellat" (un bordado de oro), "ab ret" (con red de la cual no se especifica si ésta se encontraba en los extremos o en toda la pieza) y uno del que se indica que se hallaba en mal estado (todos ellos pertenecían a Jacob Monbopés), un "pasafuga" (bufanda oscura de Joan Llorenç) y un sombrero oscuro de fieltro (también del último). Jacob Monbopés tenía muchas camisas (7 masculinas y 2 femeninas) y Joan Benet Puig un "upus" (por el nombre no se ha podido llegar a determinar de que tipo de prenda se trataba), realizado con tela de mezcla de lana y lino con aplicaciones de satén.

También aparecen varias "gonellas" propiedad de Joan Llorenç. Una de trapo de mezcla forrado con pieles de raposas ("raboses") y otra con abotonadura, cuya tela era un tejido de burel; un sayo de mezcla y sin mangas (Joan Benet Puig) y una capa ("capó") de trapo marrón forrada de tono rojo con los perfiles negros (también de Joan Llorenç).

Por los datos recopilados, es probable se trate de listados de bienes incompletos, debido a que en tales inventarios faltan algunas ropas fundamentales. Lo cual nos lleva a suponer que la mayor parte de éstas se donaba directamente a familiares o amigos a los que se les debía favores, a los pobres; o bien se incluían directamente entre los objetos destinados a ser subastados públicamente. Existe también la posibilidad de que se omitieran por otras causas, tales como por el escaso interés o valor que tenían para

«Anuario de Estudios Medievales», 34/1 (2004), pp. 307-355.- ISSN 0066-5061. 
aquel que hacía el inventario, o bien debido a que en muchos de tales inventarios de la época no se llevaba a cabo una explicación exhaustiva de todos los bienes de cada persona.

Las joyas. Cabe señalar que las joyas eran un tipo de adorno muy empleado tanto por los ceramistas como por los vidrieros. Solían contar normalmente con varios objetos de valor, aunque su número no era abundante. Además colgaban piedras buenas en los vestidos. El ladrillero Pau Figueres guardaba unos acabados para ser añadidos a un traje que consistían en una representación de unos personajes ahogados con unas aplicaciones de piedras falsas y perlas. La pieza donde éstos detalles se reunían pesaba: "1 onsa, 8 argensos" y llevaba 18 granos. Recordemos que el valor de las joyas dependía del peso.

Los ceramistas. Algunas personas depositaban piedras preciosas o perlas sin montar en los joyeros, los cuales también podían ser de forma circular. El escudillero Antoni Rosell se hallaba en posesión de: un zafiro y 6 perlas. Por el tipo de explicaciones resulta difícil saber si se trataba de piedras sueltas o montadas. Así el mismo Antoni Rosell tenía una "pedra sapina ab guarnició dargent", es decir una piedra con detalles de plata, que probablemente pertenecería a un broche. Lo mismo ocurre con Pau Figueres, quién conservaba un "papagay de or en que hi ha en lo mitg del pits una esmeralda fina y a les espatlles un diamant fals" (un papagayo de oro con una esmeralda en una cara y detrás un diamante falso. Pesaba 11 argensos y medio), al hallarse decorado por las dos caras es muy posible que se tratara de un colgante y no de un broche, pero todo son suposiciones. Igualmente hemos encontrado una cruz de plata con un crucifijo, del que desconocemos su función exacta, pues aunque se trata de un elemento religioso, podía servir bien para rezar, o como colgante. El tipo de objetos más frecuentes eran: las hileras de perlas, que podían ser de varios tamaños, e incluso hallarse combinadas con otros materiales: "filet de perlas ab senyals blaus" (tanto Bernat Marquès como Antoni Rosell), las cadenas de oro (Bernat Marquès), las cromadas de dos vías o tiras (Pau Figueres, tenía una que pesaba 7 onzas y 14 argensos); que tanto podían ser para colgar al cuello, como para llevar en el brazo; en otras ocasiones aparecen las manillas ("manilles", Probablemente era el nombre que recibían los brazaletes) y debía ser normal su uso. Éstos podían ser lisos (Joan Codina) o bien con 4 "vergues" o partes (como la de Antoni Rosell que pesaba 4 onzas y 15 argensos). Había también correas ("corretjas") de plata (Bernat Marquès) En los brazaletes no sólo se empleaba 
el oro y la plata, sino que hemos localizado uno de coral con guarniciones de oro ("un bras de coral". Antoni Rosell).

El uso de anillos era corriente. Casi todos se hallaban en posesión de uno o dos y Antoni Rosell contaba con 5. Los anillos podían ser lisos: de oro o plata, o bien tener algún acabado; en uña, en aguja con un rubí, o en aguja con una esmeralda. La aplicación de piedras era muy normal. Unos llevaban un zafiro, otros una turquesa, o granates, etc... Aunque no se consideraba una pieza totalmente generalizada aparece en muchos inventarios. El nombre: "anell", "anyell" o "ancat" nos lleva a confusión pues no se sabe si tal denominación corresponde a un anillo o a un brazalete. Aparecen tales términos por ejemplo en el inventario de Marià. En cambio, los pendientes no abundaban. Sólo Marià guardaba dos, que debían ser de su mujer, con unas amatistas iguales, lo que nos lleva a pensar que se trataba de un juego o par.

Finalmente se han observado descripciones de objetos difíciles de clasificar. Eufrasina Serdana contaba con dos "vergueras" o varillas, una de oro con un diamante y otra con las armas de los Bohigas. La segunda podía consistir en alguna prenda, o bien algún recuerdo donado por parientes, pues parece que se representaba un escudo de armas.

Los vidrieros casi no poseían objetos de valor, tales como joyas, lo cual resulta un tanto insólito. Únicamente Joan Llorenç tenía una cruz de ámbar con el contorno de oro y seis perlas pequeñas, con fines devocionales o bien de adorno. Y el mercader de vidrio Joan Benet Puig un turques azul (no se indica si se trataba de una pieza suelta o bien de algún tipo de objeto tal como un broche, un colgante, etc...).

Algunos objetos de valor y curiosos. Ocurre lo mismo que con las joyas, en los domicilios de ceramistas había normalmente algún objeto de oro, varios de plata, en cambio su uso era mucho más limitado en los vidrieros.

Los ceramistas tenían piezas de vajilla valiosas, que sólo debían emplear en ocasiones muy especiales: cucharas de plata (de tamaño mediano o grande), a veces con un acabado de marfil. Algunos artesanos sólo contaban con una o dos (probablemente para servir: Joan Codina, Pau Miralles), otros con 7 (Marià) o 12 (Antoni Rosell) y éstas solían hallarse depositadas en un cofre, al igual que las tazas. Había tazas de plata, lisas o bien con el nombre de Cristo en dorado (Antoni Rosell), $u$ otras decoraciones tales como las fortificaciones de un Castillo (Pau Figueres), tazones con orejas ("cindella") de plata (Antoni Rosell) y copas de oro (Pau Figueres), o de plata (María), cuyo tamaño podía ser diverso. Otro elemento interesante era una especie de 
protector de mesa ("agno") de plata para poner la comida encima. Elisabeth tenía uno con una decoración en la que se combinaba el nombre de Cristo y en el otro lado se hallaba el cordero pascual, un salero de plata y dorado (Antoni Rosell), una azucarera de plata (Marià), una aceitera ("cetrot" o "setrill") de plata (Antoni Rosell). Como útil que completaba el servicio se encontraba un candelabro de plata (también de Marià) y varias campanas de plata; una de ellas poseía la cadena de plata (Marià y Pau Figueres), probablemente servía para avisar a los demás miembros de la familia. Había también objetos diversos: un llavero de plata (Marià) y una plata ("patena") de oro con San Jerónimo y la Ascensión de la Virgen (Joan Codina) cuyos fines eran litúrgicos; asimismo, se empleaban botones de plata, Marià tenía una docena de los mismos, lisos, destinados a ser cosidos en alguna chaqueta o pieza de vestir.

En cuanto a los vidrieros, los objetos pertenecientes al servicio de mesa de plata, únicamente se han localizado en casa de Valença de Mont. Entre los mismos cabe mencionar una taza ("anap") de plata y cinco cucharas. En cambio sentían una cierta predilección por los objetos curiosos o poco frecuentes, los cuales no ha sido posible localizar en las viviendas de los ceramistas con tanta regularidad. Así, contaban con ramas de coral sin pulir (tal vez para usar en la elaboración de alguna joya. Joan Llorenç), e incluso el mercader de vidrio Joan Benet Puig conservaba una mola para pulir coral, pues este producto servía para elaborar rosarios, collares, etc... Algunas piezas de tocador completaban esta serie de útiles: una ungüentera femenina y un pincel de seda blanca para pintarse las mujeres el rostro, junto a una cuerda de mano de seda y dos adornos que podían haber pertenecido a alguna bolsa y unos llaveros de seda de Damasco, probablemente de importación; uno de los cuales era de tono violeta. Todos estos objetos pertenecían a Joan Llorenç.

La diferencia de gustos entre un grupo de artesanos y otro puede ser debida a cuestiones económicas, pues es probable que los ingresos de los ceramistas, debido a la mayor demanda de este tipo de productos, fueran más elevados; aunque también pudiera tratarse de un deseo por parte de los mismos de ascenso social, mediante el cual se aproximaban a las capas sociales más acomodadas, tales como la media y la alta burguesía.

El dinero guardado en casa. No todos guardaban dinero en sus casas, pues algunos preferían llevarlo al banco o la "taula de canvi". Dinero en efectivo solamente había en tres viviendas. Antoni Rosell tenía solo un ducado 
de oro guardado en una bolsa, Eufrasina Serdana se hallaba en poder de 3 ducados de oro y en la tercera vivienda la suma era más abundante. Recordemos que se trata del matrimonio formado por el vidriero Bernat de Mont y Valença que vivieron en el primer cuarto del siglo XV. En este caso la esposa, tras la muerte del marido, contaba con bastante dinero en su poder: 118 reales de plata de Barcelona a razón de 18 dineros por cada real $(=14$ libras, 2 sueldos), 27 reales de Barcelona a razón también de 18 dineros y 20 dineros metidos dentro de un saquito y un cofre ${ }^{25}, 115$ florines de Aragón (cuya equivalencia pesados era de 59 libras, 6 sueldos barceloneses), 20 florines de oro de Aragón (= 7 sueldos y 6 dineros de Barcelona) y 19 florines ( $=2$ sueldos y 6 dineros de Barcelona) también en un saquito y cofre. Podemos destacar que guardaba por separado los reales de plata de Barcelona y los florines de oro de Aragón.

\section{LOS OBJETOS DE CERÁMICA}

En los domicilios de ceramistas y vidrieros había una serie de objetos que formaban parte del utillaje doméstico, o al menos que se hallaban entremezclados con éstos. Es bastante abundante la localización de cerámicas en las casas de ambos grupos de artesanos, sobre todo cuando se trataba de útiles de cocina y de servicio de mesa. Aunque no se daba de manera generalizada, la presencia de los mismos, pues no todos poseían objetos idénticos, sino que en muchos casos, los ejemplares eran muy variados: uno tenía dos platos, otro una aceitera, otro un cántaro. Sin embargo, cabe indicar que algunas piezas eran de uso más común que otras tales como los fogones, las ollas, los jarrones o los cántaros. En cambio, los cuencos, copas, aceiteras, fruteras, muchas veces sólo se han localizado en uno de los domicilios. Además nunca se menciona si llevaban una cubierta de esmalte plúmbico, apenas surge descrito el tono del esmalte de la pieza, ni su decoración o tamaño. Asimismo, se comentan aspectos vinculados a su uso o función, o si eran objetos de importación. Cuando se desarrolla la explicación sobre los aspectos relacionados con las obras elaboradas por ceramistas y vidrieros, si que se aportan algunos de estos datos.

\footnotetext{
${ }^{25}$ Además nos hallamos con una equivalencia poco frecuente, pues el real de plata solía equivaler a 2 sueldos. No es el caso aquí, sino que equivale a 18 dineros. Cabe recordar que los sueldos y dineros barceloneses eran de plata rebajada.

«Anuario de Estudios Medievales», 34/1 (2004), pp. 307-355.- ISSN 0066-5061.
} 
En los inventarios correspondientes a ceramistas, aparece la cerámica a veces designada de un modo genérico: "una sort de obra de terra" (Joan Codina, Elisabeth Bramona y Margarida Bonarres), sin especificar los objetos y normalmente esto sucede cuando consisten en ejemplares de escaso valor o calidad. En cuanto a las piezas de cocina algunos tenían: fogones de tierra, que podían ser pequeños, o bien haber sido manufacturados en otra población: de Junyent (el de Joan Codina). Para guisar empleaban: ollas o cazuelas, si bien eran más abundantes las ollas y no se indican las características de tales objetos. Para la preparación de alimentos y el almacenamiento de productos se utilizaban: los morteros (de diversos tamaños), algunos tenían la mano de madera, las aceiteras ("setrills". No muy frecuentes), las jarras aceiteras, o las destinadas a contener el grano, las aceitunas, etc.. que tanto podían guardarse en la sala-cocina, como en la despensa y cuyas formas eran variadas. Algunas constaban de tapadera, e incluso un grifo.

El servicio de mesa incluía: escudillas o cuencos ("escudelles"), platos, platas, cobertores e incluso copas realizadas en cerámica (Antoni Calbus tenía dos), fruteras, etc.. Los platos podían ser diversos; existían los "perdiguers" (para comer carne) y se ha encontrado una plata de cobre importada de Pisa propiedad de Elisabeth Bramona. Para recoger, depositar o beber se empleaban los botijos (las denominaciones que se usaban eran "cantir" (cántaro, con un asa y más adecuado para transportar) , "canter" (cántara, con dos asas para almacenar productos), o "cantaret" (de menor tamaño) y la denominación guardaba relación con la forma del objeto. Uno de éstos era de reflejo dorado, lo cual muestra su introducción paulatina en las casas "un cantaret daurat" (Margarida Bonarres lo había guardado con otras cosas, y esto puede ser debido a que no lo utilizaba con regularidad). Otras piezas eran: los "pitxells", las "alfabies" (alfabias) que consistían en jarras, cuyos nombres dependían igualmente de su forma específica o de una terminología local; la segunda procedía del mundo musulmán.

Para la confección de pan u otros productos existían los moldes de cerámica: "un mollo de terra per a fer serenes" (un molde de tierra para hacer sirenas) y "un mollo de terra per a fer llaons" (un molde de tierra para hacer leones) poseía Bartomeu Espasa. Se producían moldes, no obstante, para otras finalidades, como los de Elisabeth Bramona, que se hallaban guardados en una caja de madera y eran de importación: "mollos de rajola valenciana", probablemente habían pertenecido a su marido, que los empleaba para imitar este tipo de productos procedentes de Valencia. 
Con usos diversos, pero básicamente destinados a la limpieza (para lavar o lavarse partes del cuerpo tales como las manos y la cara), se fabricaban los "librells" (lebrillos), las "bacines" (bacinas) y los "bugaders" (lebrillos grandes) que eran contenedores de forma más ancha y plana, aunque casi nunca se indica su tamaño y carácter. Había uno de cerámica sujetado a la pared en casa de Antoni Calbus, y para el baño utilizaba el "balsi" (bacín) o comuna (también en casa de Antoni Calbus); el último consistía en una pieza muy poco corriente.

Los niños contaban con los juguetes de cerámica, denominados "fireta", hallados en varias viviendas. Es posible que Bartomeu Espasa confeccionara tales obras, pues tenía 8 juegos. En cambio, Margarida Bonarres, probablemente disponía de algunas piezas sueltas para jugar sus hijos. Como ejemplar curioso cabe mencionar una capillita religiosa con una escultura de cerámica dedicada a San Francisco (Margarida Bonarres). Si bien no era frecuente que este tipo de objetos fueran efectuados en cerámica. Asimismo, se han localizado una serie de botes de farmacia azules en una habitación de la vivienda de Marià, pero no se dan más detalles sobre los mismos, ni se sabe si en ellos se guardaban productos. Aunque en el siglo XVII estos conjuntos se daban de manera habitual.

En cuanto a las obras destinadas al uso exterior se encuentran las floreras (Margarida Bonarres tenía 4), los fragmentos de caño ("canons"), empleados en ocasiones para extraer agua de las fuentes, como en el caso de Bartomeu Espasa.

Dentro del ámbito de los vidrieros. El uso de cerámica en los domicilios era muy abundante. Si bien de fogón solo hemos hallado uno en casa de Joan Llorenç, la utilización de objetos de cerámica en la cocción de alimentos tales como: ollas, cazuelas, paellas con su tapa ("giradora"), astas ("asts") o palos para asar la carne, parrillas ("graelles") era corriente. Para preparar éstos también contaban con: los morteros de tierra (aunque eran más frecuentes los de piedra), las aceiteras, los embudos, las servidoras o cortadoras grandes, las escurrideras ("tremostera". La única descrita era de tierra blanca, pero no se sabe si se refería a la tonalidad del barro o del esmalte, los botes, etc...

Los botes servían para guardar productos tales como: el azúcar, la confitura, las bolas de grasa para cocinar, etc. ("graxoneres" era el nombre que recibían en catalán las piezas destinadas a depositar estas bolas y parece que acostumbraban a emplearlas, pues han salido citadas más de dos). En cuanto a los botes se les denominaba: "pot" o "noell" y en la mayor parte de 
los casos se indicaba su uso: "pot de confitar", "pot petit e un noell altre per fer confitures". Aunque en estos casos la forma del bote no era relevante. Uno de los ejemplares empleados se había destinado al azúcar, pero tenía una forma muy similar al usado para la confitura. Sin embargo, normalmente este tipo de objetos habían sido pensados para depositar en los mismos confituras de elaboración propia debido al mayor número de veces en que se expone tal función. Se indica su color en una ocasión: Joan Llorenç había guardado en una caja dos botes blancos, los cuales tal vez no se habían diseñado para tal fin, sino para poner productos farmaceúticos, si bien desconocemos más detalles.

En cuanto a las servidoras, se ha encontrado una pieza de importación procedente de Málaga ("Malica"), de gran tamaño que pertenecía a Valença de Mont. También las ollas, podían servir no sólo para calentar la comida, sino para guardar alimentos. Podían hallarse en la despensa, como en el caso de una que formaba parte del utillaje de Valença de Mont. Para depositar el pan existían cestas de tierra (Joan Benet Puig contaba con varias) y para la protección de víveres los cobertores o tapaderas ("cubertera") de tierra (Joan Benet Puig tenía dos en propiedad y Joan Llorenç otra). Asimismo, las jarras se empleaban para almacenar productos y en muchos casos la denominación que recibían venía determinada por su uso: "gerra oliera" (para el aceite), "gerra ferinera" (para la harina), "per tenir aygua" (para el agua). La "gerra fornera", cuya capacidad era de unas 3 cuarteras aproximadamente, contaba con un agujero en la parte inferior para poder introducir combustible y poder calentar en la misma los alimentos. Éste tipo de jarras tenía una función doble: depósito y cocción de un producto; además en el ejemplo citado se menciona su capacidad, aunque las había de diversos tamaños.

Para almacenar también alimentos, aunque su uso podía hallarse destinado al servicio de mesa cabe destacar: los cuencos o escudillas ("escudelles") que podían ser "grasolenques" (es decir de un barro de gres especial), o "gresolades" ("de gresol" o más anchos de arriba). Vemos como en un caso la calificación se da por el tipo de barro y en el otro por la forma del objeto. Era una pieza muy corriente: Valença de Mont tenía 9, Joan Llorenç otras 9 y Joan Benet Puig 12 de importación procedentes de Valencia y 6 platas de tierra, probablemente todas ellas para vender. En el inventario aparecen las escudillas mencionadas en dos grupos de 6 , por consiguiente, es muy probable que se tratara de objetos de características diversas, o bien que presentaran una decoración distinta. Los platos tampoco eran todos similares, Joan Llorenç tenía 4 ejemplares y Joan Benet Puig 2 de tamaño grande 
procedentes de Malica (Málaga) con un acabado oscuro o cenefa. Desconocemos si los últimos formaban parte de la vajilla y eran empleados en grandes celebraciones, tenían una finalidad decorativa, o se hallaban expuestos para su venta a terceros.

En cuanto a los demás ejemplares se encuentran como contenedores de víveres: la cántara ("canter") con sus hierros, el "poal" (había uno de tierra verde. Con un asa en la parte superior y exclusivo para líquidos), la alfabia (se ha localizado una de pequeñas dimensiones). El lebrillo y el bacín también formaban parte del utillaje. Planeados específicamente para la limpieza existían los lebrillos grandes ("bugader") de tierra, cuyo uso se daba con frecuencia (Valença de Mont, Joan Llorenç y Joan Benet Puig tenían uno en su casa) y de los cuales ya hemos hablado con anterioridad. Dos llevaban esparto a su alrededor ("enserpellats") y uno tenía una cubierta de madera. Los fabricaban en diversos tamaños y uno de ellos había sido importado de Valencia. En ningún caso éstos se hallaban sujetos a la pared, o al menos este detalle no se indica.

Finalmente se elaboraban los candelabros de tierra para iluminar (denominados "canalobre" o "llumaner"), cuyo tamaño era variado. Joan Llorenç contaba con un "canalobre de terra corredis sotil"; es decir, no sujeto a la pared y de pequeñas dimensiones. Éstos no se empleaban exclusivamente en la mesa durante la comida, sino que servían para alumbrar.

Como objetos poco comunes podemos destacar las cajas de ladrillo. Debían ser pequeñas. En una de ellas se había depositado un pincel de seda ("una cassa de rajola quadrada") y la otra había sido pintada a rayas ("barres") rojas y blancas. Ambas eran de Joan Llorenç y si bien la primera debía destinarse a la cosmética, la segunda es muy probable que sirviera como joyero o bien para guardar dinero.

El uso de estas cajas no se encontraba generalizado, ni el de otros productos tales como los candelabros de cerámica, las cestas del pan o los embudos. Podía ser que en un domicilio se localizaran dos o tres y en los demás ningún ejemplar. Además las jarras, escudillas, platos o platas o lavaderos abundaban. Habían algunas ollas o morteros, y se elaboraban escasamente las parrillas o morteros, los cántaros, etc.. Nos lleva a pensar todo ello en la variedad de productos existente y en el hecho de que se usaban otros materiales para efectuar objetos similares. Se halla incompleto el utillaje de cocina y de mesa en cuanto a ejemplares de cerámica se refiere en la mayor parte de las viviendas. Cabe recordar que la madera, el vidrio, el metal o la 
piedra también podían servir como materia prima, aunque en el caso de los ceramistas, ellos mismos pudiesen elaborar la pieza.

\section{LOS OBJETOS DE VIDRIO}

A pesar de que los objetos de vidrio no eran tan usuales en las casas como los de cerámica y su tipología se hallaba más restringida, también se han obtenido algunos ejemplares. En cuanto a los inventarios de ceramistas, en varias ocasiones no se especifica cuales son los utensilios que manejaban, sino que se indica la existencia en general de varias piezas de vidrio ("una sort de vidre" aparece mencionado en los documentos correspondientes a Bartomeu Espasa, Joana Baltasar, Margarida Bonarres). Únicamente se alude a su estado de conservación o calidad. En cambio, en el caso de Elisabeth Bramona a continuación se precisa y se indica que se trata de ollas y tazas y. en el de Antoni Calbus hay además tazas, botellas, botes y cántaros con pitorro ("brocals").

Entre las piezas de vidrio se encuentran: las tazas (normalmente tenían más de una). Así por ejemplo Joan Codina contaba con 3. Las botellas también aparecen en algunas ocasiones. Como objetos menos habituales existían: la frutera (Joan Codina), las ollas (Elisabeth Bramona), los botes (Antoni Calbus), un frasco ("flasco". Marià), una lámpara ("llàntia". Antoni Calbus) y un orinal de vidrio con la cubierta de paja (Antoni Calbus). Se observa, por consiguiente, un repertorio que no se repite en todas las viviendas; tampoco se dan más detalles. Únicamente se describe el tamaño de 2 botellas (Bartomeu Espasa) y se indica si son grandes o pequeños 2 botijos ("barrals"), pero en las demás ocasiones no se dan apenas explicaciones. Del frasco, se precisa su empleo para depositar ganchos. Las demás veces las descripciones son muy simples y no constan aspectos relacionados con la tonalidad, la decoración, ni más detalles. Al tratar la descripción de la lámpara se destaca que no falta ninguna parte, ni los complementos ("ab son guarniment").

Cabe señalar, de todos modos, que es muy probable que fueran piezas de uso corriente pues se encuentran en las dependencias de la casa tales como la cocina, las sala/despensa, la bodega, excepto la lámpara que se hallaba en una de las habitaciones dormitorio. Tampoco consta que se encontraran guardadas, por lo tanto, debían ser objetos sencillos o poco lujosos. Como un elemento curioso y más valioso, Elisabeth Bramona guardaba un trozo de 
cristal, del cual se desconocen más detalles, pero podía tratarse de una pieza que formara parte de un juego.

En cuanto a los vidrieros, si que existe una mayor tendencia a depositar tales obras dentro de armarios o cajas. Aunque no exclusivamente, el mercader de vidrio Joan Benet Puig tendía a depositarlos dentro de muebles tales como el "tinell" o bien en armarios de sala. Además los comentarios que aparecen son más amplios y aumenta, lógicamente, la variedad de objetos. Para líquidos se utilizaban: las botellas (Valença de Mont y Joan Llorenç), los botijos (Valença de Mont) y las tazas (Joan Llorenç y Valença de Mont). Para la cocina además había: saleros (Joan Llorenç), botes (Joan Llorenç, Joan Benet Puig) la mayoría para confituras o azúcar, aunque en uno de ellos se guardaba un trozo de tela de lino, y frascos (Valença de Mont). Tampoco se menciona el tamaño casi nunca: "poc" o "petit" (pequeño) y "gran" (grande) y ocasionalmente se da algún dato sobre el estado de conservación "barral ab les tuberes esquinsades" (indica con ello que el botijo se halla roto) o "barralet ab cuberta" (en este caso describe tamaño y comenta algunas características de la pieza).

En vidrio también se realizaban piezas para iluminar: faroles ("faronet". De Valença de Mont), lámparas ("llàntia". De Joan Llorenç) y detalles decorativos tales como: pomos ("poms") que debían ser para los acabados de la cama o de algún mueble (Joan Llorenç) y una lágrima, también correspondiente a algún objeto (Joan Benet Puig), acaso lámpara.

\section{EL OBRADOR Y LA TIENDA}

En primer lugar cabe señalar que muchas veces no se observa una división clara entre el espacio destinado a la venta de productos y el taller, o al menos tal división no aparece delimitada en todos los inventarios. Algunos artesanos empleaban el porche de su casa para fines comerciales y en él distribuían las obras. Asimismo, otros poseían un recinto reservado para tal fin. Los pasillos, patios y otras habitaciones hacían la función de almacén de objetos y de materia prima.

Los ceramistas. Existe una gran variedad de material destinado a la manufactura y comercialización de productos; igualmente, había un amplio repertorio de formas cuyo conjunto constituía su obra.

El material. Los bancos, tablas, mesas plegables servían para depositar las piezas a medio elaborar (su número oscilaba entre 4,3 o $1, \ldots$ ).

«Anuario de Estudios Medievales», 34/1 (2004), pp. 307-355.- ISSN 0066-5061. 
Los recipientes grandes ("bugaders") se empleaban para manipular el material y los capazos ("cabassos") que eran de esparto, al igual que las grandes jarras ("gerrams") para guardar la cerámica y transportarla con mulas u otros animales. Estos podían darse en cantidades bastante amplias $(6,4,3, \ldots$ piezas). Por ejemplo Joan Codina tenía 18 cestones ("covens de gitar") vacíos, probablemente destinados al almacenamiento. También constan las materias primas tales como la tierra o el barro. Antoni Rosell contaba con "mitja grossa de terra"; es decir unas 6 docenas o unas 72 unidades, alguna de las cuales ya llevaba una jornada de amasado ("un jornal de pastar"), pues la tierra que extraían de las canteras debían prepararla para que se pudiera manipular y trabajar con ella fácilmente. Igualmente guardaban barniz, aunque no se sabe de que tipo era. Antoni Rosell tenía 24 arrobas de barniz bueno (lo cual es una cantidad muy elevada, pues cada arroba equivalía a 26 libras y 1 libra eran 400 gramos). Una romana cuyo peso grande de plomo era de 3 quintales y 1 arroba (recordemos que 1 quintal equivalía a 41,60 kg.). La descrita era de Antoni Rosell, pero muchos artesanos poseían una en su casa, para pesar productos no sólo de cerámica sino de diversa índole. Además, el empleo de plantas olorosas tales como la "ginesta" (genista. 40 haces que eran de Marià ), el "romani" (romero. 8 docenas también de Marià) y el "atzeriol" (acerolo. 16 arrobas) que se incluían en el horno en el momento de cocer las piezas y así avivar el fuego, era común. En el inventario de Marià se especifica que almacenaba leña para tres hornadas o cocciones. Las astas ("asts" y "forcats") servían para depositar la citada leña en el horno y eran útiles que se han hallado con regularidad en diversos documentos para tal fin: "unes forquetes de fira per courer obra" (Bartomeu Espasa).

Como dato relevante existía el "fractum" u obra rota o en mal estado, que guardaban para su venta, aunque parezca raro. Recordemos que éste servía para llenar las bóvedas de iglesias y otras construcciones de la época. Tanto Antoni Rosell, como Marià lo poseían en grandes cantidades: 5 "grosses" (unas 720 piezas) y 6 "grosses" y 6 docenas (unas 732 más 72 piezas. O sea 804 obras) respectivamente; lo cual no resulta extraño, pues se trataba de la reunión de los productos defectuosos correspondientes a muchas cocciones debida a un mal secado o a una cochura errónea. Recordemos que las circunstancias en las que se efectuaba la manufactura y las características de la cocción condicionaban un elevado grado de obra defectuosa: con deformaciones, roturas o grietas en las cerámicas, lo cual impedía su venta en el comercio normal. 
Los instrumentos del obrador. Los bancos, tablas y astas o pinzas se hallaban en diversos ámbitos pues tanto podían emplearse para depositar las piezas tras su manufactura, como para ponerlas a secar al sol, o distribuirlas antes de su cocción. Las tablas que se han encontrado dentro del recinto destinado a obrador, o en sus alrededores son muy numerosas (Bartomeu Espasa, Pere Bonarres, Marià, Antoni Rosell y otros usaban tales útiles). Así por ejemplo Marià tenía cuatro docenas de estas tablas y Bartomeu Espasa catorce docenas.

Antes de proseguir la reconstrucción de un taller, se puede detacar que según los datos obtenidos, parece que tenían obrador Bernat Marquès, Bartomeu Espasa, Pau Miralles, Pere Bonarres, Marià, Antoni Rosell, un escudillero anónimo. De los demás artesanos no se han localizado productos, ni artefactos que nos permitieran considerar que también contaban con uno, por lo tanto podían hallarse colaborando en los obradores de otros ceramistas del mismo oficio.

Los útiles comunmente encontrados, a pesar de que pueda parecer extraño, consistían en moldes de diversos tipos, tales como de teja girada y de teja común con curva (Bernat Marquès guardaba uno aunque era jarrero) y otros de baldosa valenciana dentro de una caja de madera (Joan Bramona, probablemente los había obtenido por compra o como prenda). Se han encontrado unos de madera con el. escudo de armas del General, destinados a elaborar detalles para el Palau de la Generalitat, en casa de Bartomeu Espasa. No se ha obtenido más información de como debían ser tales moldes. En cambio se sabe que los moldes podían confeccionarse de madera, de metal o bien de cerámica y los había de diversas tallas o tamaños. El escudillero Bartomeu Espasa guardaba unos cuantos de tales caracteres para realizar obra, aunque desconocemos más datos y Pere Bonarres poseía algunos para ejecutar piezas de "fireta" (feria) que se habían depositado dentro de un cesto.

Asimismo se hallaban en poder de varios ceramistas moldes de madera y de cerámica para efectuar sirenas de dos medidas: grande y pequeña, leones también de tierra (Bartomeu Espasa y los había depositado junto a las piezas de cerámica), tortugas (Pau Miralles, también se hallaban entre los útiles del taller) y dos tortugas de plomo (un escudillero anónimo los tenía en la tienda) que eran propiedad de otro ceramista. Por las explicaciones, no parece que este tipo de moldes se destinara a la elaboración de las formas de las obras, sino a su decoración, pues parecen más bien "trepas" o plantillas.

«Anuario de Estudios Medievales», 34/1 (2004), pp. 307-355.- ISSN 0066-5061. 
La rueda era otro utensilio de madera muy común, si bien no abundan los detalles que se aportan sobre las mismas. Contaban con ésta: Pere Bonarres, Bernat Marquès, Pau Miralles y Bartomeu Espasa. A pesar de que Pere Bonarres sólo tenía una, Bernat Marquès poseía dos de madera de pino, Pau Miralles contaba con 4 ejemplares. Las de Miralles se hallaban asentadas en el suelo y tenían asientos. Existían ruedas de mano, pero es muy probable que las demás también poseyeran características similares a las de Pau Miralles, pues el torno de pie se encontraba plenamente introducido en los siglos XV y XVI. También empleaban algunas herramientas para manipular el barro durante la ejecución de las piezas y Margarida Bonarres había depositado éstas ("sos arreus") en las golfas tras la defunción de su marido, pero no se han obtenido los nombres, ni los caracteres, de estos instrumentos de trabajo.

Los cedazos ("garbell") podían hallarse destinados a pasar la tierra ("garbell de pastar terra", Bernat Marquès), si bien su utilidad inicial se hallaba vinculada al almacenamiento de pan. Las cestas servían para depositar la obra cocida, como ya se ha indicado, y los cuencos ("cossi", "baranguera" o "librell"/ lebrillo) estaban preparados con barniz para la inmersión de las piezas en los mismos. Antoni Rosell conservaba "una baranguera gran plena de vernis passat", lo cual sugiere que en ocasiones el barniz si se guardaba mucho tiempo se estropeaba. Como noticia poco común un escudillero poseía tres quarterolas de media carga con vinagre, el cual tanto podía hallarse reservado para su venta, como a su uso en la manufactura de obras de cerámica, pues este material servía para pegar fragmentos, disimular defectos y grietas, entre otras cosas.

Igualmente se hallaban en posesión de "rodells de terra" (rodillos). Por la denominación equívoca tanto podía tratarse de fragmentos de tierra amasada preparados para elaborar las piezas, como de los instrumentos aptos para acondicionar el barro. Únicamente se han localizado en el taller de Bernat Marquès; en cambio, Bartomeu Espasa poseía cajas con tierra. Pero se desconoce si éstas incluían pedazos de tierra para elaborar objetos, o bien piezas ya obradas y tal vez cocidas. Finalmente tenían hierros ("una sort de ferrets que posan per fer scudelles". De Pere Bonarres) empleados para separar una pieza de otra dentro del horno con el objetivo de que no se enganchara el esmalte de una con el de la otra. A través de esta fuente no se han podido obtener más detalles sobre el tipo de hornos, pero es muy posible que los mismos fueran comunes a varios artesanos; es decir, que no tuvieran 
hornos todos ellos sino que, debido a sus grandes dimensiones, los compartieran.

Las noticias obtenidas no nos exponen algunos aspectos importantes, pero lo que si es cierto es que la obra tras su cocción se almacenaba temporalmente: "una fornada de diverses coses de terra cuita la qual ha cuit" (Joan Codina) y que tanto podían efectuar encargos, como productos destinados a la venta directa. No se especificaban siempre sus características: "Tresentes y vint grosses, quatre dotsenes d'obra" (unas 46080 piezas y 48 más, en total 46128 ejemplares), cantidad que resulta bastante insólita, /aunque es posible que fuera aproximada). Asimismo hallamos "una grossa de roda per a courer" en el obrador de Marià; es decir unas 144 piezas ya elaboradas, pero no acabadas, aunque desconocemos en que etapa del proceso se hallaban. Tampoco sabemos la cantidad aproximada de cerámicas que podían incluir en cada hornada.

La tienda. El uso de albaranes de la obra entregada, pagada o no abonada se daba con normalidad (Joan Codina y Joan Bramona los utilizaban). Existían además escaleras de madera de diversos tamaños ("escala de gat ab vuyt escalons", Bartomeu Espasa tenía una transportable con ocho escalones), las tablas de madera se empleaban como mostrador (Joan Bramona) y las cestas con el género eran enseres habituales.

A continuación se tratará de establecer una clasificación del tipo de objetos y piezas que elaboraban, los cuales se hallaban descritos por unidades, docenas o "grossas" (una "grossa" equivalía a 144 unidades).

Las piezas de importación. Dentro del repertorio destinado a la venta incluían objetos que no habían sido elaborados en sus talleres, aunque es probable que no todos los ceramistas dispusieran de ellos para su venta: platos grandes de Málaga y escudillas comunes de Málaga (Bartomeu Espasa tenía 6 piezas y 9 elementos respectivamente). Éstas fueron luego imitadas en los obradores locales como veremos, debido a la aceptación que tuvieron.

Las piezas destinadas a completar construcciones arquitectónicas. tejas verdes para el acabado del tejado o las junturas del alero ("mitja grossa de priar cases". Antoni Rosell), pomos de tejado barnizados en verde para decorar ("22 poms de teulada entre grans i xics envernisats de vert. Bartomeu Espasa), pies de tejado con calabazas esmaltadas (" 10 peus de posar de teulada ab deu carabases totes de terra envernisades". Bartomeu Espasa), una teja carenera de tierra (también para el tejado. Bartomeu Espasa). En cuanto 
a estos elementos decorativos, todos ellos habían sido efectuados por Bartomeu Espasa: 17 leones para poner en la barandilla de la escalera, 2 docenas de tortugas lisas o con pitorro, 60 vigas de techo ("cabirons") barnizadas por fuera con esmalte verde y destinadas a la puerta de la Diputación del General o Palau de la Generalitat, una gárgola esmaltada de verde, una pica de agua bendita barnizada sin especificar el tono, 4 docenas de pasamanos de barniz verde también para la escalera y un pequeño retablo encofrado con la imagen de la Virgen y su hijo Jesús.

Las piezas para la ingeniería del agua, denominadas "catulls", "cadufos", o "catufos" o recipientes para extraer agua de las norias (2 docenas y 4 piezas. Antoni Rosell). En un inventario se describen como catufos de Sinia (pertenecientes a la máquina empleada para hacer subir el agua y recogerla del rio. Bartomeu Espasa guardaba 2 "grosses" o sea 288 ejemplares y 2 docenas más). Se fabricaban también tuberías o canales de tierra grandes y pequeñas (100 tubos había realizado Bartomeu Espasa) y tuberías de embudo (eran las dispuestas en los ángulos (24 piezas. Bartomeu Espasa). Las tuberías o "canons" recibían diversas denominaciones según su uso y tamaño: cañerías de brazo (6 docenas), de brazo y angulares ("colzats". 6 ejemplares), de muslo ("cuxa". 3 docenas, probablemente más amplios), en forma de codo ("colze" o dobladas en ángulo. 14 piezas). Recordemos que había también algunas de alpaca. Todas habían sido elaboradas por Bartomeu Espasa. En cambio, Marià había manufacturado 3 docenas de picas barnizadas para depositar el agua de la higiene personal.

Las piezas destinadas al exterior y al establo o gallinero: macetas ("torratxes" o "torreta". Bartomeu Espasa tenía 3), regadoras (40 de Bartomeu Espasa), piezas para comer las gallinas (13 ejemplares también hechos por el último artesano citado) y dos bacines ("bassines xiques" para poner las piadas, del mismo autor).

La obra para los niños o la feria ("fireta" o "botiges"), que podía ser de tierra blanca o no, con asas o complementos y de diferentes medidas. 80 9 docenas guardaba Bartomeu Espasa.

La obra común y esmaltada. Existían una serie de piezas de uso común. En algunos inventarios solo se indica que consistían en formas sin barnizar o bien obra "aspra" (áspera) de color negro. Siendo descrita 
mediante cantidades tales como "grosses" o "covens", ambas bastante amplias. Por ejemplo Joan Codina guardaba 16 "grosses" y media, y 40 "covens" o cestas. Si su tamaño era pequeño las denominaban "menut". En algunas ocasiones debía tratarse de juegos o decoraciones tricolor: obra de dos $\mathrm{u}$ obra de tres se indica. Las cantidades conservadas eran muy grandes: 2 "grosses" y 10 docenas o más. Joan Codina solía guardar las piezas en cestas y tenía 5 conteniendo cerámica barnizada de color verde.

En cuanto a los calentadores de cama y los fogones, solían ser de índole rústica. Aunque no existe una descripción precisa. 19 fogones había elaborado Antoni Rosell para la cocción de alimentos, junto a 48 calentadores de cama de tamaño normal, y otros 34 calentadores grandes un escudillero anónimo. Asimismo las baldosas destinadas a depositar encima de ellas las lámparas eran ejemplares de una modalidad especial, y debían efectuarse en grandes cantidades, pues Antoni Rosell tenía 2 "grosses" y media almacenadas. Vemos a través de esta clasificación como muchos ceramistas se hallaban especializados en un determinado tipo de productos.

Las piezas decoradas y de reflejo metálico. Las letras góticas y calados eran una decoración común en los siglos XV y XVI, pero tanto podían efectuarse en las obras de barniz blanco y azul, como en las creadas utilizando la decoración conocida como la técnica musulmana del reflejo metálico. Antoni Rosell había llevado a cabo numerosos "letrats" o piezas con letras ( unas 11 "grosses" y 6 docenas).

Con decoración azul se realizaban platos de payés (" pagès blau", "plats blaus", "pagès rodó"). Es muy probable que con el término "pagès" no se aludiera a una decoración especial en la que apareciera un campesino, sino a un tipo de platos o piezas tal vez rústicas, las cuales debían ser de uso muy común pues las ejecutaban tanto Marià, como Antoni Rosell, y también el escudillero anónimo. La obra azul también era ejecutada por Joan Codina. La cerámica de estas características se producía en grandes cantidades: 18 "grosses" y 3 docenas de obra azul, " 10 dotzenes pagès blau" o " 11 grosses pagès blau" por citar algunos casos. Se trataba de piezas esmaltadas y los platos podían ser de diverso tamaño.

Los objetos de reflejo metálico recibían en los inventarios el nombre de obra de plata o dorada, o bien la denominaban "talla de argent", aunque no se describe tampoco el tipo de decoraciones que llevaba incorporada y muchas veces se desconocen cuales eran las formas realizadas por los citados artesanos, pues a través de esta fuente sólo se tienen nociones sobre la 
cantidad de obra producida, o sobre su carácter metalizado: "11 grosses y 2 dotzenes plata fina", "7 dotzenes plata prima grana", etc.. En una ocasión se destaca su fondo blanco: " 3 grosses dobra blanca talla de argent", o si se consiste en una pieza de calidad: " 23 grosses i 2 dotzenes talla de argent fi". Se sabe que no eran de importación todas, sino que se trataba de productos locales, pues en algunas ocasiones, constan en los inventarios obras preparadas con tales ingredientes, pero todavía no cocidas. Las mismas se encontraban en los domicilios de Antoni Rosell, Joan Codina, Bartomeu Espasa. Confeccionaban tales piezas con total seguridad Marià y un escudillero anónimo. Los ejemplares más usuales que hacían con esta técnica eran las escudillas comunes, los tazones de oreja y las platas. Es cierto que contaban con una gran cantidad de cerámica acumulada de esta índole. Marià debía producir una variante por lo que se indica: " 6 grosses de galati daurat per a courer pintat": hacía a pincel obra dorada de galatí.

Las piezas de cocina y la vajilla. De confección más rústica, al igual que las de limpieza y los contenedores de líquido y grano. Las primeras se hallaban destinadas tanto a la cocción, como al almacenamiento de víveres. Había los siguientes tipos, cuyas denominaciones venían determinadas por su uso, aunque no se dan detalles sobre las mismas, ni se indica si llevaban barniz: Las ollas son calificadas del siguiente modo "olles manco" (3 docenas. Antoni Rosell), "olles de tres" ( 2 piezas. Antoni Rosell) y "olles grans" (2 docenas y media de ollas grandes. También Antoni Rosell). Algunas de las cuales las vendían a 2 dineros la pieza cuando eran de tamaño grande y sólo 1 dinero si eran pequeñas. El precio de las cazuelas parece similar y el de las "greixoneres" o recipientes para poner la grasa de cocinar también, a no ser que fueran de grandes dimensiones. Antoni Rosell elaboraba estos dos últimos tipos de pieza y los guardaba en pequeñas cantidades. $\mathrm{Y}$ finalmente se mencionan los "gresolets" (́según el texto, Pere Bonarres tenía algunos montones). Es muy posible que se tratara de unos recipientes. En algunos casos resulta difícil por el término empleado llegar a deducir cual era el objeto al que aludían: "capalevats", probablemente tapadoras o algún útil destinado a la bebida (5 docenas tenía Antoni Rosell).

Asimismo, había algunos saleros (Pere Bonarres, un escudillero anónimo y Marià los elaboraban en grandes cantidades: 3 docenas y media, 4 docenas o 1 "grossa" respectivamente). Los de Marià llevaban decoraciones a pincel: "una grossa de salers per a coure pintats". Asimismo se fabricaban aceiteras ("setrills". 8 de Bartomeu Espasa), recipientes para medir el aceite

«Anuario de Estudios Medievales», 34/1 (2004), pp. 307-355.- ISSN 0066-5061. 
o "setras" (2 de Bartomeu Espasa), y una quesera ("formatgera"). La última muy poco común había sido efectuada por Antoni Rosell.

Apenas se han encontrado escudillas, pero si muchos platos manufacturados por Joan Codina, Antoni Rosell, Marià. Veamos los platos que denominaciones recibían según sus características: de común ("comú") o rústicos, de servir, para comer perdices y carne ("de perdiguer"), finos o bien acabados, pequeños, con decoración, y de cuerda seca. Todos ellos se hacían en grandes cantidades 18 "grosses", 21 docenas, 14 docenas, etc... Ocasionalmente se obraba alguna cesta del pan ("penadera". Antoni Rosell).

Aunque no abundaban, también se realizaban copas (Antoni Rosell, "tres copetes").

Las piezas de limpieza e higiene. Se efectuaban: los recipientes o lebrillos grandes ("bugaders" o "bugades") para tal fin (4 poseía Antoni Rosell), los lebrillos ("librells") y los bacines ("basins") de diversos tamaños. Los lebrillos podían ser de dimensiones medianas o pequeñas y su aspecto final hallarse más bien acabado o menos ("librells fins", "librells comuns"); los producían Bartomeu Espasa y Joan Codina. Las bacinas las creaban Bartomeu Espasa, Marià, o un escudillero anónimo, al igual que los anteriores productos, se efectuaban en grandes cantidades y en tamaño diverso: pequeño, mediano y grande. Habían las bacinas de barbero con un agujero para introducir el cuello, efectuados por Marià. Como dato curioso el escudillero anónimo contaba con 20 docenas de bacinas, cantidad bastante considerable; lo normal era tener acumuladas unas 2 docenas de tales obras.

Entre los ejemplares más atípicos se hallaban las escudillas que se empleaban en los partos: "escudelles de partera", que llevaban un barniz normalmente blanco. Las elaboraban Bartomeu Espasa (6 docenas permanecían depositadas en el taller) y Antoni Rosell (10 docenas)

Las piezas para contener líquidos y áridos. Las alfabias consistían en unas jarras de origen musulmán. Desconocemos si éstas se producían en Cataluña o eran de importación, pero se han encontrado algunos ejemplares: 2 pertenecientes a Antoni Rosell y 5 de Bartomeu Espasa. Los cántaros ("canters" y "càntirs" de dos o una asa. Antoni Rosell tenía 5 del primer tipo), algunos llevaban tapa y un barniz verde hasta la mitad del cuerpo (6 docenas y 3 docenas. Antoni Rosell), los "pitjers" o "pitxers" pieza del repertorio fabricado por Marià, un escudillero anónimo y Joan Codina. De los últimos los había de índole áspera ("aspres"), probablemente sin esmalte (un 
escudillero anónimo) y con barniz y decoración (Marià). Las cantidades almacenadas eran amplias ( 1 "grossa", 7 docenas, 2 docenas, 35 ejemplares). Otra variedad eran las botellas ("botillas"), también efectuadas en diversos tamaños (10 docenas. Bartomeu Espasa), los frascos ("flascum". 7 "grossas" de Marià) y las jarras ("jarreta" o "gerreta" o "gerra”). Las citadas jarras eran elaboraban por los siguientes artesanos: Joan Codina, Marià y Bartomeu Espasa, según consta y las producían en grandes cantidades: 10 docenas, 2 docenas, 1 jarra respectivamente. La pieza mencionada en último lugar sabemos que era de tierra blanca, probablemente se refería al tipo de barro, aunque podía tratarse de una alusión a su aspecto y entonces llevar una capa de barniz. Se han localizado unas jarras grandes o "gerrans", cuya utilidad se desconoce, pues tanto podían servir como contenedores de aceite, grano $\mathrm{u}$ como objetos de cerámica para otro fin (Antoni Rosell).

Los botes de farmacia. Si bien su producción no era tan abundante, ni frecuente como la de jarros o platas, también se daba. Marià había confeccionado 70 ejemplares, de los cuales no se indican más detalles.

La obra dificil de clasificar. En ocasiones los datos que tenemos no nos permiten llegar a saber exactamente de que tipo de piezas se trataba, pues se exponen del siguiente modo: " 5 dotzenes de pinzell", " 8 grosses en mig blanc", "34 grosses galati" etc..., pero estas noticias nos permiten deducir algunas características tales como el uso de decoración a pincel, el empleo de barniz blanco y en cuanto al galatí suponemos que consistía en una determinada forma, esmalte o decoración: "galati scaldat e guarnit sense coure" o "galati pintat blau sens courer". Aparece citado este término varias veces en los documentos de Marià, Antoni Rosell y un escudillero anónimo y su producción era bastante abundante.

Igualmente existe en el inventario de Antoni Rosell la cerámica denominada "de compte"; a través de tal concepto no se puede llegar a tener una noción clara de la misma. Pues tanto podía tratarse de motivos heráldicos, como de un tipo de decoración: "dos grosses e mija de compte", "25 dotzenes de compte" ("compte" equivalía al concepto cuenta).

Finalmente aparece el nombre "ladriolas" que tanto podría significar guardiolas, como "rajolas" o baldosas de un tipo determinado. Consta que Antoni Rosell elaboró 8 docenas, las cuales guardaba en su obrador. 
Algunas equivalencias o precios. A través del inventario de Eufrasina Serdana se ha hallado un albarán en el cual se habían anotado algunos precios, a causa de que el escudillero Gabriel Serta le debía a ella una cantidad de obra: Los datos obtenidos corresponden al primer cuarto del siglo XVI, fueron redactados alrededor de 1525 y son los siguientes:

- $1 / 2$ "grossa" de platos valorados en 15 sueldos (cada plato costaba 2,50 dineros, o 2 dineros y 1 malla).

-1 "grossa" de escudillas por 14 sueldos (cada escudilla valía 1,16 dineros aproximadamente).

-1 "grossa" de escudillas blancas o 7 sueldos (cada escudilla blanca equivalía a unos 0,58 dineros).

-1/2 "grossa" de copitas o 6 sueldos, 6 dineros (cada copita se vendía al valor aproximado de 1,08 dineros).

-8 tapaderas a 2 sueldos, 8 dineros (cada tapadera costaba 4 dineros).

-10 tapaderas pequeñas a 3 docenas la tapa por 2 sueldos, 6 dineros (cada tapadera pequeña se podía adquirir por 3 dineros).

- 1/2 docena de lebrillos pequeños de ala girada o 2 sueldos (cada lebrillo se ofrecía a 4 dineros).

Aunque sólo se puede establecer una valoración aproximada, debido a que no se aporta ninguna descripción sobre las características de la piezas, es muy probable que la compra de productos en grandes cantidades llevara consigo un considerable descuento y que siempre se hallara sometida al regateo, pues los precios no debían ser fijos. La lista anterior no nos permite saber si se trataba de objetos de calidad o bien de obra común, pero más adelante se intentará realizar una comparación empleando las noticias extraídas de las subastas de bienes.

Los vidrieros al igual que los ceramistas poseían en muchos casos taller y tienda propios, en los cuales no sólo vendían su propia producción, sino otros productos. Habían tenido obrador Bernat de Mont, Joan Llorenç y Jacob Monbopés; en cuanto a la tienda o espacio para la venta, el único que no contaba con una era Jacob Monbopés, los dos artesanos anteriores y el mercader de vidrio Joan Benet Puig, por los datos obtenidos, parece que almacenaban un número amplio de objetos propios y en el caso de Joan Llorenç, bastantes piezas de cerámica. En cambio, Joan Benet Puig aunque conservaba algunas cerámicas, había recogido una mayor variedad de productos para su venta. Aunque no era corriente tener un libro de cuentas, algunos contaban con éstos, como Joan Llorenç y el mercader de vidrio Joan 
Benet Puig. Los aspectos relacionados con estos libros, con anotaciones, ya se han tratado anteriormente.

Los útiles del taller y el material. Consistían en grandes cantidades de vidrio. Jacob Monbopés había comprado: 47 "grosses" por 42 libras, 6 sueldos (debían ser piezas o fragmentos que no se vendían a peso, sino por unidad, pues cada "grossa" equivalía a 144 piezas. Cada porción valdría por consiguiente unos 10 sueldos). El coste era elevado si lo comparamos con los precios de la cerámica antes mencionados, pero se trata del valor atribuido a esta materia a finales del s. XVI. No se detalla en que estado se encontraba la misma, ni como era, pues los vidrieros solían adquirir fragmentos que eran reciclados para, con la pasta, elaborar nuevos objetos. Además tenían "árboles", que debían ser una especie de bastones, para transportar el vidrio (Jacob Monbopés tenía 3 ejemplares). En cuanto a las balanzas podían ser de madera, o de paja con esqueleto de madera y se especifica claramente que servían para pesar el vidrio. Las hallamos en la vivienda de Bernat de Mont, Joan Llorenç y Jacob Monbopés. Era corriente contar con un par de juegos (Jacob Monbopés y Joan Llorenç los poseían) con pesas de hierro habitualmente de 1 libra, y 1 libra y media probablemente ("ab dos pesos de dos lliures y mija entre tots").

La tienda. Se hallaba compuesta por algún mostrador: "una taula de una peça de fusta que servia per tenir los vidres". En el cual se depositaban los objetos. Joan Benet mercader contaba con uno, al igual que Joan Llorenç: "un taulell de quatre perques", del cual se especifica que tenía cuatro patas. Las tablas ("posts") servían también para trasladar y depositar la obra. Valença de Mont guardaba un par de tablas, un banco y una alfombra ("stora") de gerd (un tipo de vegetal).

Entre las piezas destinadas a la venta se hallaban los siguientes grupos: los barrales de vidrio de diversos tamaños: grande, mediano y pequeño (Valença de Mont y Joan Llorenç). Se especifica a veces su dimensión por "corters" (o "quarter", una medida de capacidad, que equivalía cada una a 7,52 litros):"de un corter", "de sis corters o entorn cuberts de palma" y se acostumbraba a cubrir estos objetos con palma para evitar su rotura. Es posible, por las medidas citadas, que uno de ellos fuera muy pequeño y el otro grande. En cuanto al número oscilaba entre 1, 2, 5, o bien 1 quintar $(41,60 \mathrm{Kg}$.); en este último caso la cantidad no se daba por ejemplares, sino por peso. También, en ocasiones, se calculaba por "grosses" 
y de un modo general, estableciendo el cálculo por unidad, sin detallar de que tipo de objeto se trataba. Asimismo, dentro del ámbito de las creaciones elaboradas en este material se hallaban también las siguientes formas: los brocales, las escudillas de crisol ("gresolers"), los tazones de orejas, las copas con agujeros, los saleros esmaltados, y los "almerratges" ("almorratges" o almorranas) o cántaros de vidrio con esmaltes. Todas estas piezas no eran consideradas objetos de lujo, sino obra común; es probable, que llevaran decoraciones superpuestas, pues la persona que hizo el inventario las describió con el término "esmeltades" o esmaltadas. Igualmente, había algunos elementos complementarios tales como: el "storp" o forro de palma para vidrio empleado para preservar las botellas de nave (Joan Llorenç) entre otras, y las sarrias de esparto, de carácter triangular, que servían para sujetar las piezas al burro y poder transportarlas (Joan Llorenc).

Los mismos vidrieros fabricaban también útiles que no pertenecían a la vajilla, a la cocina, ni para líquidos, sino que complementaban las necesidades y los detalles de la casa, tales como las castañas de vidrio (las cuales podían emplearse para lámparas y otros fines) y que acostumbraban a cubrirse con "verga" para evitar su rotura. Se observa, por lo tanto, que existía una mayor tendencia entre los vidrieros, que entre los ceramistas a proteger las piezas, aunque se hallaran dispuestas para la venta directa y no se tuvieran que transportar lejos. Puede consistir en una costumbre de algunos artesanos, como de Joan Llorenç, pues la mayor parte de sus objetos estaban cubiertos con fibra vegetal.

Las piezas de cerámica también podían ser vendidas en las tiendas de los vidrieros. Así ocurría en la de Joan Llorenç. Asimismo, Joan Benet Puig, el mercader de vidrio, tenía un par de cántaros o "canters" con sus hierros, probablemente éstas se hallaban destinadas a servir de medidas y 6 jarras aceiteras; por consiguiente, se trataba en este segundo caso de ejemplares sueltos.

En el comercio de Joan Llorenç, en cambio, se hallaban expuestas las formas que se relacionan a continuación: jarras para aceite (6 piezas), un lebrillo verde y dos embudos de estaño para las siguientes medidas: "mig corto e cortà e mallal" (recordemos que el "corto o quarto" equivalía a 1,062 litros, el "cortà o quarta" a 5,79 litros y el "mallal" a 15,175 litros) y se empleaban para mesurar el aceite también. Una escurridera o "tremostera" de tierra blanca, 2 ollas de tamaño mediano para ir al fuego. Y otros objetos muy variados tales como: 2 bolsas de arenques ("arangades") forradas, 5 conos de caña de tamaños diversos grandes y mediano, 2 manteles blancos, 1 perol, 1 
trozo de tela de lino y estopa de 15 canas y otro trozo de tela de algodón de 15 canas y media. Seguramente la mayor parte de estos útiles se destinaran a la venta, lo cual nos permite deducir que en su tienda se podían comprar cosas muy diferentes, pero también es posible que alguno de estos objetos fuera para el uso personal, aunque se encontrara dentro del citado espacio.

\section{LOS PRECIOS Y VALORES DE ALGUNOS OBJETOS}

Éstos han sido obtenidos a partir de las subastas de bienes efectuadas por los citados artesanos, o bien por sus familiares tras su muerte. En cuanto a los ceramistas tenemos las de: Joan Codina, Pau Figueres, un escudillero anónimo y de las viudas de Joan Bramona, Pere Bonarres y Antoni Baltasar, todos ellos citados al principio del trabajo. Los vidrieros que subastaron sus propiedades fueron: Bernat de Mont, Joan Llorenç y Jacob Monbopés. De los mismos se han seleccionado: cerámicas, vidrios, materias primas, las joyas y objetos de plata, algún retablo o estatua. Se consideraran todos conjuntamente, pues el objetivo primordial reside en llegar a tener una noción del valor económico de tales productos.

Las cerámicas. Cabe distinguir la obra cruda de la cocida, pues también podía ser vendida la primera, que era comprada casi siempre por otro ceramista que la finalizaba. Nos quedan datos sobre la subasta de la obra de un escudillero anónimo, la cual fue adquirida por otro escudillero llamado Guillem Pau y la equivalencia que tuvo lugar fue la siguiente: 12 sueldos.

-16 "grosses" de obra corriente a 2 sueldos la "grossa" = 1 libra, sueldos.

-6 docenas de jarras "pitxer" obra común a 2 dineros la pieza $=12$

-varias ollas negras sin barnizar (no especifica más) $=11$ libras.

-2 docenas y media de bacinas a 2 sueldos la pieza $=5$ sueldos.

-20 "grosses" de pages a 2 sueldos la "grossa" $=2$ libras.

-8 "grosses" de galati a 2 sueldos la "grossa" $=16$ sueldos.

-15 docenas de obra de plata barnizada a 4 sueldos la "grossa" $=5$ sueldos.

-2 "grossas" y media de plata sin barnizar a 2 sueldos la "grossa" $=5$ sueldos.

«Anuario de Estudios Medievales», 34/1 (2004), pp. 307-355.- ISSN 0066-5061. 
-2 "grossas", 4 docenas de plata sin barnizar a 2 sueldos la "grossa" $=4$ sueldos, 8 dineros.

-(no se lee) "grossa" letrada barnizada a 4 sueldos la "grossa" y media, junto a payés barnizado (no se lee) "grossa" = 1 libra, 10 sueldos.

En este caso resulta un poco difícil saber cual era el valor real del producto acabado; pero sirve como un dato a tener en cuenta para conocer el valor aproximado de las piezas a mediados del siglo XVI. Se observa que la obra de reflejo metálico, tenía un precio similar al de algunas cerámicas decoradas con letras y las piezas de obra común costaban la mitad que las otras. De todos modos, en conjunto, se vendieron a un precio bastante barato, pues se trataba de grandes cantidades de género.

En cuanto a la obra cocida y acabada, se han obtenido noticias de varias subastas: Bernat de Mont (principios del siglo XV), Joan Codina (principios del siglo XVI), un escudillero anónimo (mediados del siglo XVI), Elisabeth Bramona vda. de Joan Bramona (finales del siglo XVI), junto a Jacob Monbopés (correspondiente a fines del último siglo citado). Por consiguiente se pueden establecer unas delimitaciones cronológicas:

1) Principios del siglo $X V$ :

-1 "alfabreguer" $=8$ dineros (era un pote para contener alfábrega o menta de pastor).

-3 jarras de aceite vacías $=1$ sueldo (cada jarra costaba 4 dineros).

-1 jarra pequeña de aceite vacía $=1$ sueldo, 5 dineros.

-1 jarra de aceite vacía $=2$ sueldos, 7 dineros.

-8 piezas de obra de Málaga 3 grandes y 5 pequeñas $=2$ sueldos, 8 dineros (cada obra valía 4 dineros)

-10 piezas de obra de Málaga $=2$ sueldos, 1 dinero (cada ejemplar se vendía a 2,5 dineros, o 2 dineros y 1 malla).

Se trata de un documento de 1412, a través del cual se puede apreciar como la obra de importación procedente de Málaga, no se vendía a un precio superior a la realizada en Cataluña, pues una pieza común con un barniz costaba entre $1 / 2$ sueldo y 1 sueldo, según las características y el tamaño de la pieza. Además las jarras de aceite, de elaboración muy común entonces, en un periodo posterior dejan de formar parte de la tipología habitual propia de las subastas y las piezas procedentes de Málaga, ya no se encuentran en las mismas; lo cual permite suponer que o bien eran muy escasas, o bien al haber subido su consideración se las quedaban los familiares o parientes y no las subastaban a terceros en la mayor parte de los casos. Vemos como a principios del siglo XV las piezas de Málaga se vendían al mismo precio o un 
poco más caras que las jarras de aceite, lo cual resulta un tanto sorprendente. Asimismo, a principios del siglo XVI, según muestra otro inventario al que nos hemos referido anteriormente, los platos, escudillas y copitas mantenían casi una tarifa idéntica, o bien ésta era ligeramente inferior a la de principios del siglo XV. Aspecto que también se puede observar en algunos casos que se van a exponer a continuación.

2) Principios del siglo XVI:

-40 arrobas de obra común (sin especificar) a 4 sueldos la arroba $=$ 8 libras.

-2 cántaros (no se lee) = libra, 4 sueldos. 6 dineros).

-2 jarras pequeñas para tener aceitunas $=1$ sueldo (cada jarra valía

-5 arrobas de jarras a 8 sueldos la arroba $=2$ libras.

-2 "grosses" de obra de tres a 1 libra la "grossa" $=2$ libras, 10 sueldos (cada obra de tres equivalía a 1,6 dineros).

-3 "grosses", 10 docenas de obra de tres (no se sabe si de tres colores o un juego de tres piezas) $=1$ libra, 18 sueldos, 4 dineros (cada obra de tres costaba 7,8 dineros).

-3 "grosses" de obra de plata a 14 sueldos la "grossa" = 2 libras, 2 sueldos, (cada obra de plata se vendía a 1,16 dineros aproximadamente).

Según se puede observar, el cálculo se hacía o bien por peso, en arrobas (o 26 libras), o bien por unidades o grupos de unidades: "grossas" (= 144 unidades), docenas ( $=12$ ejemplares), o piezas. En este caso resulta más difícil establecer equivalencias, pero se intuye un ligero aumento en la consideración de las obras de tres (tal vez tricolor), si establecemos una comparación con las obras de reflejo, cuyo precio podía ser muy similar o incluso inferior a las tricolor, y al que costaban los cántaros y la obra común. Si se tiene en cuenta el albarán de Gabriel Serra, las diferencias entre el coste de las piezas de reflejo metálico y el de las escudillas o platos no eran tan desproporcionadas. Esto nos lleva a considerar que en aquellos momentos la cerámica decorada a pincel de varios colores, prevalecía sobre la efectuada con sulfatos y en cocciones reductoras para obtener los tonos cobrizos y dorados. Es posible que se introdujera la tricolor más tarde en Cataluña que la de reflejo, pues la procedente de Málaga (tratada en el apartado dedicado a principios del siglo $\mathrm{XV}$ ) debía llevar una decoración metalizada y, al consistir la tricolor en una obra más novedosa, esto podía conllevar una ligera reducción del precio de coste de la anterior.

3) Mediados del siglo XVI:

«Anuario de Estudios Medievales», 34/1 (2004), pp. 307-355.- ISSN 0066-5061. 
-170 "grosses", 2 docenas de obra común a 11 sueldos, 6 dineros $=$ 97 libras, 16 sueldos, 11 dineros.

-19 jarras "pitxers" a 10 sueldos la docena $=15$ sueldos, 10 dineros, (cada "pitxer" equivalía a 1,2 sueldos).

-2 docenas de jarras, 3 piezas a 4 sueldos la docena $=9$ sueldos (cada jarra valía 3,96 dineros).

-14 docenas de bacines a 15 sueldos la docena $=3$ libras, (cada bacín o bacina se vendió por 9,6 dineros).

-7 docenas de calentadores ("capalentadors") pequeños a 3 sueldos la docena $=1$ libra, 1 sueldo, (cada calentador costaba 0,33 dineros. Era pues muy barato). sueldos.

-17 (no dice nada) de calentadores grandes a 5 dineros la pieza $=7$

-11 "grosses", 7 docenas de tipo plata fina (reflejo metálico o "talla dargent") a 14 sueldos, 6 dineros la "grossa" $=8$ libras, 7 sueldos y 6 dineros, (cada obra de plata se valoraba en 1,2 dineros).

-7 "grosses", 7 docenas de plata fina a 1 libra, 11 sueldos, 6 dineros $=11$ libras, (cada pieza costaba 2,8 dineros).

-3 docenas de obra de plata fina a 8 sueldos, 6 dineros la docena $=$ 10 sueldos, 6 dineros, (cada objeto se vendió a 2,8 dineros).

-3 docenas de obra de plata fina pequeña a 3 sueldos, 6 dineros $=$ 10 sueldos (no se lee mas). (cada pieza pequeña de plata se obtuvo por 1,6 dineros).

-3 docenas y media de obra de plata fina grande a 5 sueldos la docena $=17$ sueldos, 6 dineros, (cada obra grande de plata se consiguió al precio de 4, 9 dineros).

-5 "grosses" y media de payés azul a 8 sueldos la "grossa" $=2$ libras, 4 sueldos, (cada cerámica de payes costaba 0,6 dineros).

-12 "grosses" de galatí a 18 sueldos, 6 dineros la "grossa" $=16$ libras, 11 dineros, (una pieza de galatí eran 1,5 dineros, o sea 1 dinero y malla).

En la oferta de bienes del escudillero anónimo se observa como los lotes similares se vendieron a precio semejante. Debía haber unos precios más o menos comunes o establecidos, aunque a través de este método de venta los mismos podían oscilar. Además, en comparación con la obra cruda a medio acabar, las cerámicas ya cocidas y finalizadas subían mucho de coste porque las cocciones eran difíciles y una gran cantidad de género se estropeaba durante la fase de cochura. 
Cabe señalar que, a partir de los datos extraídos de la última subasta, queda patente la modificación de precios y el mayor valor que tenía la obra de reflejo metálico con respecto a la obra de payés azul, el galatí, etc.., aunque el citado valor siempre se hallaba supeditado a las dimensiones. Podríamos decir que se mantuvo a mediados de siglo XVI, bastante el precio de las piezas de plata con respecto al alcanzado a inicios del mismo siglo. Asimismo, la de galatí era un poco más cara que la de payés azul. Como aspecto a tener en cuenta, parece como si los bacines, las jarras o los "pitxers" - de los cuales no se indica ni su decoración, ni su carácter fino o rústico- tuvieran una mejor valoración que algunas obras de reflejo a mediados del siglo XVI, y no es probable que ello se debiera todavía a la vulgarización de su producción. Puede ser que se tratara de un medio para proteger la producción local, frente a la introducción del estilo foráneo. Además la manufactura tricolor procedía en sus orígenes de Italia. Recordemos que Cataluña estuvo vinculada á esta zona durante el periodo de la Corona Aragón y posterior, por lo tanto, es probable que este tipo de obra no lo consideraran un producto tan ajeno a su cultura, como la dorada.

Existen una serie de piezas subastadas, del mismo periodo, que considero a parte por ser ejemplares curiosos, tales como los balines realizados en barro cocido, el "fractum" u obra rota, o en mal estado probablemente extraído de una cocción defectuosa y que se reaprovechaba para llenar las bóvedas de los edificios. Igualmente, se da el caso de una pieza o jarra que se vendió con el producto (miel) dentro. Veamos sus precios:

-4 docenas de balines a 15 sueldos la docena $=3$ libras.

-20 "grosses", 2 docenas de "fractum" a 7 sueldos, 6 dineros la "grossa" = 6 libras, 17 sueldos (por cada obra defectuosa se cobró 0,6 dineros).

-18 "grosses", 3 docenas de "fractum" a 7 sueldos, 6 dineros la "grossa" = 6 libras, 7 sueldos (también en este caso se pagaron 0,6 dineros por cada pieza rota).

-1 jarra ("burneta") con un poco de miel $=2$ sueldos.

Otro ejemplo escasamente frecuente es el de la venta de "fractum", pues a pesar de la diferencia de cantidad entre uno y otro lote del producto la compraron Miquel Sadorni y otra persona al mismo precio de 0,6 dineros aproximadamente. En los demás casos, siempre se estipuló un coste similar y por consiguiente no hago constar tal información.

4) Finales del siglo XVI:

- una serie de obra, platos y escudillas $=10$ dineros 
- una serie de obra, platos y escudillas y una fuente de vidrio $=2$ sueldos, 8 dineros.

Son los únicos datos obtenidos, que por consiguiente, no nos permiten establecer conclusiones sobre el valor económico exacto de cada ejemplar.

Las piezas de principios y finales del siglo XVI se vendieron a ciudadanos, de los cuales no se especifica el oficio. En cambio, las de mediados del siglo XVI, algunas de las mismas fueron compradas por el escudillero Miquel Sadorni, tal vez para revenderlas a particulares y un pequeño lote pasó a manos de otro escudillero denominado Antic. El resto las obtuvo un tal señor Ponsia, del cual no sabemos nada más y que casi siempre compró lotes totalmente similares a los de Miquel Sadorní.

En cuanto a la materia prima o material utilizado para la manufactura de obra, nos quedan noticias dispersas de mediados del siglo XVI pertenecientes al inventario del escudillero anónimo quién subastó barniz y carbón que le compró el escudillero Guillem Pau:

-2 cargas de carbones a 18 cientos (o 1800 carbones) a 4 sueldos cada 100 las obtuvo por 3 libras, 12 sueldos. Por el contrario, el barniz lo vendieron a peso: 36 arrobas de barniz para moler (sin preparar) a 12 sueldos la arroba se consiguió por 21 libras, 12 sueldos. Lo cual refleja que el barniz no era barato.

Los demás datos corresponden a fines del siglo XVI y éstos nos permiten conocer el precio de unas tablas para depositar las piezas de cerámica y el de de una caja de patrones o plantillas para decorar las obras.

-Una caja de patrones de pintar baldosas se vendió al presbítero Antoni Bassa por 2 sueldos y 6 dineros. ro Pau Gibert.

-8 tablas para obrar las obtuvo por 4 sueldos y 2 dineros el escudille-

En comparación, las tablas a pesar de no tratarse de un objeto artístico tenían un coste casi superior al de los patrones. Si bien los segundos eran un elemento destacado para poder reproducir motivos y esto refleja que algunas decoraciones se repetían a través de este método, aunque aplicando ligeras variantes, pues en el siglo XVI la cerámica decorada era abundante. Además cabe recordar que la caja de patrones había sido propiedad del escudillero Joan Bramona y que todos los ejemplos aportados se refieren a los precios aproximados que tenían estos objetos.

Los vidrios. Apenas nos quedan datos sobre el valor económico de los objetos de vidrio. Las subastas de Bernat de Mont (de principios del siglo XV) 
y las de las esposas de ceramistas Joana Baltasar y de Elisabeth Bramona, ambas desarrolladas a fines del siglo XVI nos proporcionan algunos detalles sobre el tema. Además, a través de la documentación correspondiente a Joan Llorenç vidriero de fines del $\mathrm{s}$. XV, se puede llegar a saber cual era el precio de las tablas para depositar el vidrio.

La obra de principios del siglo XV:

- Un barral pequeño de vidrio $=5$ dineros

-Un barral grande de vidrio $=3$ sueldos, 8 dineros.

Si se comparan los costes de la cerámica del mismo periodo con los del vidrio, se observa que una jarra de aceite de un tamaño normal era más barata que un barral grande de vidrio, pero no se pueden establecer conclusiones exactas debido a la escasa información disponible en cuanto al tipo de formas y a los demás caracteres de las piezas se refiere.

El único material del que se conserva información perteneciente a fines del siglo XV son las tres tablas para guardar objetos que fueron vendidas por 6 dineros.

En cuanto a los precios de fines del siglo XVI:

Una fuente de vidrio y un poco de obra de tierra (platos y escudillas) costaban 2 sueldos, 8 dineros. Debido a que no se estableció una disgregación de estos objetos, resulta imposible establecer una valoración. Además, en la misma época un cesto con vidrio y otras cosas se equiparaba a unos 3 sueldos y 3 dineros. Por consiguiente, no se puede conocer el precio de una pieza de vidrio en el mercado.

Las joyas y la platería. A través de las subastas de estos artesanos estudiados se han hallado escasos objetos de oro y plata. Los de oro pertenecían casi todos a Pau Figueres (ladrillero de fines del siglo XVI) y una pieza de plata, también de la misma época, era de Elisabeth Bramona. Los demás objetos correspondían a vajillas de lujo y pertenecían al vidriero Bernat de Mont (principios del siglo XV).

Los ejemplares de uso doméstico del siglo XV consistían en:

-5 cucharas de plata, 3 planas y 2 torcidas con la base dorada, cuyo peso era de 3 onzas y media según peso del marco de Barcelona se subastaron por 13 sueldos la onza, por lo tanto se pagó 1 libra, 9 sueldos, 5 dineros ${ }^{26}$.

${ }^{26} \mathrm{El} \mathrm{marco} \mathrm{de} 8$ onzas era una unidad de peso de la plata y el oro. Éste equivalía antes de 1442 a 267,333 gramos y después de 1442 a 271,947 gramos.

«Anuario de Estudios Medievales», 34/1 (2004), pp. 307-355.- ISSN 0066-5061. 
-1 copa ("anap") de plata blanca pesaba 4 onzas la plata a peso de marco de Barcelona a razón de 100 sueldos, 1 dinero el marco se obtuvo por 2 libras, 19 sueldos.

A través de estos datos se observa que el valor de la plata era mucho más elevado que el de la cerámica y el del vidrio del mismo periodo, por tratarse de un objeto de lujo al igual que las joyas.

Las joyas de fines del siglo XVI, eran casi todas de oro, excepto alguna piedra preciosa y un ejemplar de plata:

- una cadena de oro de 7 onzas, 14 argensos, 10 libras, 18 sueldos la onza de peso se vendió por 51 libras, 15 sueldos, 8 dineros.

-unas manillas o pulsera de oro se valoró en 51 libras, 15 sueldos, 8 dineros.

-un collar de "verges" blancas (o canutillos enhebrados) cuyo peso era de 1 onza, 2 argensos fue obtenido por 11 libras, 15 sueldos.

-un cordero pascual o "Agnus Dei" montado en plata y fósiles, y un anillo de plata con el nombre de Jesús en cambio se dio por 4 sueldos.

-un rubí costaba 9 libras

- una esmeralda 6 libras.

Eran considerablemente más caras las piezas de oro que las de plata.

Las piedras preciosas tales como el rubí o la esmeralda poseían una mayor valoración que la plata. Aunque no resulta fácil establecer comparaciones con tan pocos ejemplares.

Los retablos y las estatuas. Se ha obtenido información a través de las subastas de Bernat de Mont, Joan Codina y Elisabeth Bramona. Por consiguiente, las noticias son muy esparcidas: de principios del siglo $\mathrm{XV}$, de principios del siglo XVI y de finales del siglo XVI.

A principios del siglo $\mathrm{XV}$, se vendió un oratorio de doble cierre con unas imágenes de Jesús en la cruz, y otras de unas mujeres con sus hijos, con su alfombra de madera, por 10 sueldos al presbítero Joan del Pozo (de Puteo).

Dos retablos de principios del siglo XVI, se obtuvieron por un precio muy desigual, aunque es muy probable que se debiera a su calidad. En uno se hallaba pintado el tema de la Salutación de Elisabeth a la Virgen y costó (falta un trozo), 6 sueldos, 1 dinero. En cambio, el otro retablo era más complejo y con más escenas, pues a un lado se hallaba San Jaime y en el otro había la Salutación de la Virgen con adornos de plata; el citado se valoró en 4 libras, 10 sueldos y 6 dineros. 
El último retablo, de fines del siglo XVI, presentaba la figura de Cristo y se obtuvo por 3 sueldos, 1 dinero. Es decir, a un precio inferior a los dos anteriores.

Estas obras guardaban una mayor consideración que los objetos utilitarios de cerámica y de vidrio, tanto si se trataba de obra común, como cuando se referían a objetos decorados. En cambio, las estatuas de fines del siglo XVI, consistentes en tres figuritas: dos de la Virgen y una de la Verónica se subastaron por 1 sueldo, 8 dineros.

A través de estas noticias se sabe que las joyas eran muy valoradas, la platería le seguía por ser sus ejemplares objetos de lujo y a continuación le sucedían las piezas de carácter religioso tales como pequeños retablos. Siendo de menor relevancia la cerámica, el vidrio y por último la escultura. Sin embargo, es posible que el ejemplo de la escultura no sea representativo. Hay que destacar además, que al corresponder esta documentación a ceramistas y vidrieros, este tipo de objetos valiosos era escaso y, en cambio, abundaban sobre todo las piezas de cerámica. Se han excluido todas las apreciaciones y precios de los demás utensilios de la vida cotidiana y que también formaban parte de los textos de los inventarios y subastas.

\section{CONCLUSIONES}

A pesar de que ya se han ido tratando sucesivamente en los diversos apartados los aspectos más característicos, se deduce a través de la información que la mayor parte de estos artesanos eran analfabetos y no sabían contar con exactitud, pues a veces los cálculos son inexactos y realizados de un modo global y no numéricamente. Esto se concluye del escaso número no sólo de libros, sino de albaranes de cuentas hallados en sus viviendas, lo cual hace suponer que los cálculos eran orales y probablemente no solían efectuar facturas o recibos.

En cuanto a los juguetes para niños eran muy escasos. Las aficiones se limitaban a la caza y a la tenencia de armas que empleaban para esta y otros fines, lo cual sugiere la existencia de una consideración y un culto hacia la lucha y la figura del guerrero. Algunos artesanos compraban más de un arma para poder emplearla en caso de guerra. Las demás actividades formaban parte del trabajo diario, tales como la agricultura, la ganadería o el desempeño paralelo de otro oficio. En cuanto a la manufactura de tejidos y 
productos de comida (el pan, la confitura, ...), eran tareas realizadas comunmente por las mujeres.

El sentido religioso se mostraba de un modo desigual, pues había personajes muy devotos y otros que apenas practicaban el culto. El número de capillas, rosarios y retablos de índole religiosa localizados en sus viviendas nos ayuda a establecer deducciones en este sentido.

Había un interés por la ropa, por vestir bien o al menos la mayoría poseía varios conjuntos. Las telas de importación y los objetos curiosos les atraían, al igual que las joyas y la vajilla de lujo formada por piezas de plata, aunque siempre contaban con algún ejemplar y nunca con un juego completo. La tenencia de joyas era desigual, pero normalmente se trataba de un símbolo de riqueza y reflejaba el deseo de aproximarse a las clases medias más adineradas.

Cabe señalar asimismo el aprovechamiento de objetos, tejidos y ropas. Una cosa vieja no era nunca desechada, se recomponía o se recosía, e incluso se revendía en tal estado, porque sabían que hallaría comprador. Además no tenían el sentido que hoy tenemos de conjunto. Las piezas desapareadas, la falta de un elemento no importaba. Era normal tener una o dos copas, no un juego; o bien uno o dos platos. Lo cual nos permite considerar que aunque las cosas semejantes, como se observa en las subastas, podían comprarse por lotes, también podían ser vendidas por unidades y de un modo separado.

Como ya se ha mencionado había un gusto por los objetos curiosos o poco frecuentes. Se valoraba su rareza, el hecho de que no todos pudieran tener acceso a aquel producto. Además a pesar de que se ejercía el préstamo y el trueque, la forma más normal de compra era el pago en dinero efectivo. Igualmente el ahorro es una característica que empezaba a mostrarse en algunos, el hecho de poder tener una cuenta en un banco o en la "taula de canvi", de poder comprar una casa o un huerto, etc... eran indicios de bienestar $^{27}$.

Los elementos relacionados con su labor $u$ oficio se encuentran incompletos. Por ejemplo, las herramientas que empleaban no constan en ninguno de los inventarios, ni otros útiles. El uso de pastadores ("pasteras"), en el caso de los ceramistas, para preparar la tierra, que es muy probable que tuvieran en la parte posterior de su casa, nunca se expone. Por consiguiente, a través de tales inventarios podemos llegar a tener una idea aproximada.

${ }^{27}$ C. Riu de Martín, Ob. Cit.

«Anuario de Estudios Medievales», 34/1 (2004), pp. 307-355.- ISSN 0066-5061. 
Sabemos que usaban plantillas para decorar las piezas, pero se nos escapan muchos detalles relacionados con el tipo de decoración que hacían, si no nos valemos de los restos arqueológicos y artísticos conservados. Lo cual no nos impide considerar, a través de estas dos fuentes consultadas, que producían en grandes cantidades, y que a lo largo de los siglos se dio una modificación de formas y usos.

Cabe recordar la escasez de inventarios localizados y estudiados hasta el momento correspondiente a estos grupos de artesanos. Además, los pocos datos extraídos de las subastas, debido a que estos documentos aparecen de un modo muy diseminado cronológicamente, no nos permiten efectuar unas conclusiones más precisas de los precios en algunos periodos históricos, ni del valor social exacto de las piezas en aquellos momentos y no en la actualidad. Parece como si algunos objetos bajaran y subieran ligeramente de valor en el mercado a lo largo de estos siglos en varias ocasiones. Pero para precisar más este ámbito sería necesario comparar las cerámicas y los vidrios con otros utensilios y útiles de la vida cotidiana localizados en las mismas subastas tales como la ropa, los alimentos u los muebles. Aspectos que quedan pendientes para un trabajo posterior y que nos permitirán saber con mayor exactitud cual era el valor económico, la importancia social y el prestigio real de los productos realizados por estos artífices. 
Sabemos que usaban plantillas para decorar las piezas, pero se nos escapan nuchos detalles relacionados con el tipo de decoración que hacían, si no nos valemos de los restos arqueológicos y artísticos conservados. Lo cual no nos impide considerar, a través de estas dos fuentes consultadas, que producían en grandes cantidades, y que a lo largo de los siglos se dio una modificación de formas y usos.

Cabe recordar la escasez de inventarios localizados y estudiados hasta el momento correspondiente a estos grupos de artesanos. Además, los pocos datos extraídos de las subastas, debido a que estos documentos aparecen de un modo muy diseminado cronológicamente, no nos permiten efectuar unas conclusiones más precisas de los precios en algunos periodos históricos, ni del valor social exacto de las piezas en aquellos momentos y no en la actualidad. Parece como si algunos objetos bajaran y subieran ligeramente de valor en el mercado a lo largo de estos siglos en varias ocasiones. Pero para precisar más este ámbito sería necesario comparar las cerámicas y los vidrios con otros utensilios y útiles de la vida cotidiana localizados en las mismas subastas tales como la ropa, los alimentos u los muebles. Aspectos que quedan pendientes para un trabajo posterior y que nos permitirán saber con mayor exactitud cual era el valor económico, la importancia social y el prestigio real de los productos realizados por estos artífices. 